2017-08-21

\title{
Mesoscale and Submesoscale Effects on Mixed Layer Depth in the Southern Ocean
}

\section{Bachman, S}

http://hdl.handle.net/10026.1/9609

\subsection{5/JPO-D-17-0034.1}

Journal of Physical Oceanography

American Meteorological Society

All content in PEARL is protected by copyright law. Author manuscripts are made available in accordance with publisher policies. Please cite only the published version using the details provided on the item record or document. In the absence of an open licence (e.g. Creative Commons), permissions for further reuse of content should be sought from the publisher or author. 


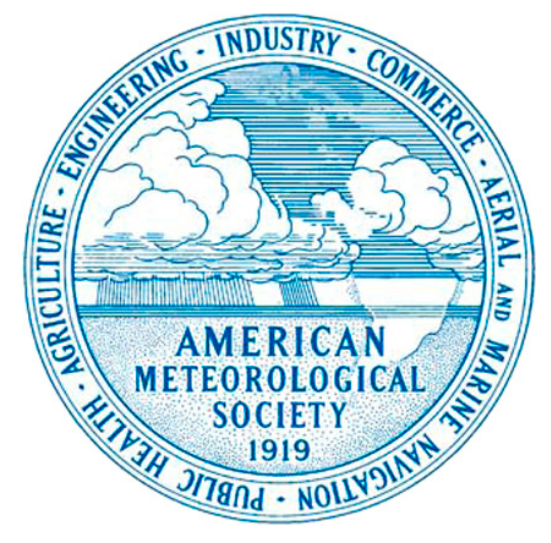

\section{AMERICAN METEOROLOGICAL SOCIETY}

Journal of Physical Oceanography

\section{EARLY ONLINE RELEASE}

This is a preliminary PDF of the author-produced manuscript that has been peer-reviewed and accepted for publication. Since it is being posted so soon after acceptance, it has not yet been copyedited, formatted, or processed by AMS Publications. This preliminary version of the manuscript may be downloaded, distributed, and cited, but please be aware that there will be visual differences and possibly some content differences between this version and the final published version.

The DOI for this manuscript is doi: 10.1175/JPO-D-17-0034.1

The final published version of this manuscript will replace the preliminary version at the above $\mathrm{DOI}$ once it is available.

If you would like to cite this EOR in a separate work, please use the following full citation:

Bachman, S., J. Taylor, K. Adams, and P. Hosegood, 2017: Mesoscale and Submesoscale Effects on Mixed Layer Depth in the Southern Ocean. J. Phys. Oceanogr. doi:10.1175/JPO-D-17-0034.1, in press. 


\section{Mesoscale and Submesoscale Effects on Mixed Layer Depth in the Southern}

\section{Ocean}

S.D. Bachman and J.R. Taylor*

4

Department of Applied Mathematics and Theoretical Physics, University of Cambridge, UK

K.A. Adams and P.J. Hosegood

*Corresponding author address: DAMTP, Centre for Mathematical Sciences, Wilberforce Road,

${ }_{8}$ Cambridge CB3 0WA, United Kingdom.

๑ E-mail: J.R.Taylor@ damtp.cam.ac.uk 


\section{ABSTRACT}

Submesoscale dynamics play a key role in setting the stratification of the ocean surface mixed layer and mediating air-sea exchange, making them especially relevant to anthropogenic carbon uptake and primary productivity in the Southern Ocean. In this paper a series of offline-nested numerical simulations is used to study submesoscale flow in the Drake Passage and Scotia Sea regions of the Southern Ocean. These simulations are initialized from an ocean state estimate for late-April 2015, with the intent to simulate features observed during the Surface Mixed Layer at Submesoscales (SMILES) research cruise which occurred at that time and location. The nested models are downscaled from the original state estimate resolution of $1 / 12^{\circ}$ and grid spacing of about $8 \mathrm{~km}$, culminating in a submesoscale-resolving model with a resolution of $1 / 192^{\circ}$ and grid spacing of about $500 \mathrm{~m}$. The submesoscale eddy field is found to be highly spatially variable, with pronounced "hotspots" of submesoscale activity. These areas of high submesoscale activity correspond to a significant difference in the 30-day average mixed layer depth, $\Delta \overline{H_{M L}}$, between the $1 / 12^{\circ}$ and $1 / 192^{\circ}$ simulations. Regions of large vertical velocities in the mixed layer correspond with high mesoscale strain rather than large $\Delta \overline{H_{M L}}$. It is found that $\Delta \overline{H_{M L}}$ is well-correlated with the mesoscale density gradient but weakly correlated with both the mesoscale kinetic energy and strain. This has implications for the development of submesoscale eddy parameterizations which are sensitive to the character of the large-scale flow. 


\section{Introduction}

Submesoscale processes play a crucial role in the evolution of the oceanic surface boundary layer. Recent work has highlighted the importance of near-surface submesoscales both as a means of transporting heat and tracers into the oceanic interior via strong vertical circulations (Pollard and Regier 1990; Rudnick 1996; Lapeyre and Klein 2006; Mahadevan and Tandon 2006), and as a mechanism for fluxing large-scale energy downscale via unbalanced instabilities (e.g. McWilliams et al. 2001; Molemaker et al. 2005; Taylor and Ferrari 2009, 2010; Thomas and Taylor 2010; D'Asaro et al. 2011). The vertical transport associated with submesoscale motions has also been shown to significantly affect primary production by redistributing phytoplankton, grazers, and nutrients throughout the water column (Spall and Richards 2000; Mahadevan and Archer 2000; Flierl and McGillicuddy 2002; Gargett and Marra 2002; Lévy et al. 2001, 2012; Lévy and Martin 2013; Omand et al. 2015).

The growing appreciation for the importance of submesoscales has spurred intensive research into a wide variety of processes which occur at these scales within the ocean surface boundary layer. There exists a rich set of instabilities and dynamics which constitute the broad class of submesoscale flows, here defined in the dynamical sense to be motions with $\mathscr{O}(1)$ Rossby and Richardson numbers and horizontal scales of $0.1-10 \mathrm{~km}$ (Thomas et al. 2008). Oceanic submesoscale motions are often associated with the presence of lateral density gradients, or fronts. These fronts arise via mesoscale frontogenesis (Lapeyre and Klein 2006) and precondition the mixed layer to a variety of submesoscale instabilities such as ageostrophic baroclinic instability (Boccaletti et al. 2007), symmetric instability (Taylor and Ferrari 2009), and centrifugal instability (Jiao and Dewar 2015), which in turn can be enhanced or suppressed through buoyancy forcing and wind stress (Thomas 2005; Taylor and Ferrari 2010). 
Because submesoscale turbulence is highly sensitive to atmospheric forcing, frontal strength, and mixed layer depth, it can be expected to vary in strength on both fast and slow timescales. Mixed layer baroclinic instability and forced symmetric instability both have growth timescales on the order of hours to days (Stone 1966; Taylor and Ferrari 2009) and are capable of restratifying the mixed layer (e.g. Boccaletti et al. 2007). Observations (Callies et al. 2015; Buckingham et al. 2016; Thompson et al. 2016) and high-resolution modelling studies (e.g. Capet et al. 2008a; Mensa et al. 2013; Sasaki et al. 2014; Brannigan et al. 2015) suggest strong seasonal variation in the strength of submesoscale turbulence, where deep wintertime mixed layers increase the available potential energy that can be released by these instabilities.

Submesoscales are also expected to be energised through a downscale transfer from mesoscale eddies, which are highly spatially variable (e.g. Klocker and Abernathey 2014). However, it is unclear how submesoscale activity might vary with the energy of the mesoscale eddy field and complex bottom topography. Rosso et al. $(2014,2015)$ used a $1 / 80^{\circ}$ regional model of the Southern Ocean to investigate the role of submesoscales in a region of complex bottom topography near the Kerguelen Plateau, and identified submesoscales using a high-pass spatial filter with a $1 / 5^{\circ}$ cutoff. Using this method they found a strong correlation between upper-ocean vertical velocities, which was used as a proxy for submesoscale activity, and mesoscale eddy kinetic energy and strain. No direct influence of topography on submesoscale features was observed, though it was argued that topographic control over the mesoscale eddy field might indirectly affect the submesoscales.

In this paper we use a series of nested high-resolution models to analyze submesoscale activity in a different location within the Southern Ocean, as part of SMILES (Surface Mixed Layer Evolution at Submesoscales; http://www.smiles-project.org/). The simulations coincide with observations collected on the SMILES project research cruise to the Scotia Sea, just east of 
Drake Passage, in April-May 2015 (Adams et al. 2017). This region is characterized by an energetic mesoscale eddy field (Frenger et al. 2015) and strong fronts associated with the Antarctic Circumpolar Current (ACC). Although mode water transformation and subduction occurs here (Sallée et al. 2010; Cerovečki et al. 2013), the role of submesoscale processes is unknown. Submesoscale motions have the potential to modulate water mass properties across the mixed layer and, therefore, may affect the oceanic uptake of tracers, such as atmospheric gases and heat.

The goal of this analysis is to investigate how and where submesoscale eddies affect the mixed layer depth by comparing the output of the nested models. To do so, we will compare output from the highest-resolution member of the series of models, which at $1 / 192^{\circ}$ (less than $500 \mathrm{~m}$ ) horizontal resolution is sufficient to resolve submesoscales, against the coarsest member, a $1 / 12^{\circ}$ mesoscale-permitting model. In this comparison, we intend to focus special attention on how mixed layer submesoscales should be identified in high-resolution models like these, and to assess how they are spatially correlated with larger, mesoscale features. The numerical model configuration is described in Section 2. Analysis of the meso- and submesocale influence on the mixed layer depth and vertical transport is presented in Section 3. Concluding remarks appear in Section 4.

\section{Model description}

In this study the MITgcm (Marshall et al. 1997a) is used to conduct a series of offline-nested simulations of the Drake Passage and Scotia Sea regions of the Southern Ocean. Each simulation is run on a curvilinear, latitude-longitude grid, and uses open boundary conditions whose configuration is described below.

The initial state and boundary conditions for the lowest resolution $\left(1 / 12^{\circ}\right)$ MITgcm simulation are provided by the Copernicus Marine Environment Monitoring Service Global Ocean 1/12 
Physics Analysis (hereafter CMEMS), which is produced by Mercator Ocean (http://marine . copernicus.eu). The domain of the $1 / 12^{\circ}$ simulation extends from $65^{\circ} \mathrm{S}$ to $45^{\circ} \mathrm{S}$, and from $110^{\circ} \mathrm{W}$ to $40^{\circ} \mathrm{W}$ (Figure 1). The flow is initialized from the CMEMS ocean state estimate for this region on 23 April 2015. The open boundary conditions are one-way nested, updated once per day, and relaxed to the CMEMS state estimate for each subsequent day over a sponge region $2^{\circ}$ wide on all edges of the domain. The timescale of this relaxation increases linearly as one approaches the edge of the domain, ranging from 30 days at the inner edge of the sponge region to one day at the boundary.

The vertical grid spacing is 5 meters over the top $100 \mathrm{~m}$ of the water column and increases by a factor of 1.1 for each level below that, up to a maximum of $50 \mathrm{~m}$. The vertical grid consists of 125 levels, thus extending down to $4600 \mathrm{~m}$. Model bathymetry is provided by the General Bathymetric Chart of the Oceans (GEBCO) 2014 global 30-arc-second ( $\sim 1 \mathrm{~km})$ product (http://www.gebco.net), and is interpolated appropriately to match the resolution of each simulation. Wind stress and surface heat forcing are provided by daily snapshots of the European Centre for Medium-Range Weather Forecasts (ECMWF) atmospheric analysis for the time period from April to July 2015 , which are interpolated from $1 / 4^{\circ}$ to the appropriate resolution. Lastly, each simulation uses a vertical viscosity $v_{v}=10^{-4} \mathrm{~m}^{2} \mathrm{~s}^{-1}$, a vertical temperature and salt diffusivity $\kappa_{v}=10^{-5} \mathrm{~m}^{2} \mathrm{~s}^{-1}$, and a combination of modified harmonic and biharmonic Leith horizontal viscosity (Leith 1996; Fox-Kemper and Menemenlis 2008) with tuning coefficients of 1.5 and 2.0, respectively. Added to this is a biharmonic horizontal viscosity which varies in strength according to the grid resolution according to $v_{b h}=0.1 \times(\Delta x \Delta y)^{3 / 2} \mathrm{~m}^{4} \mathrm{~s}^{-1}$ (e.g. Chassignet and Garraffo 2001). The K-Profile Parameterization (Large et al. 1994) is used to represent the vertical mixing of momentum and tracers in the surface boundary layer. 
The $1 / 12^{\circ}$ simulation is run from 23 April to 31 July 2015 , with daily-averaged output. The next simulation in the nesting hierarchy, at $1 / 24^{\circ}$ resolution, uses the same domain extent as the $1 / 12^{\circ}$ simulation, and is also run until 31 July 2015 . The open boundary conditions for this simulation are also provided by the interpolated CMEMS state estimate. Due to computational expense, the final three simulations in the hierarchy, at $1 / 48^{\circ}, 1 / 96^{\circ}$ and $1 / 192^{\circ}$ resolution, are run until 31 June 2015 on a smaller domain, $60^{\circ} \mathrm{S}$ to $48^{\circ} \mathrm{S}$ and $80^{\circ} \mathrm{W}$ to $40^{\circ} \mathrm{W}$. Detailed analysis is performed by time-averaging over the month of June 2015 (see below), giving an effective spin-up time of just over one month. Because the mesoscale eddy field in the $1 / 12^{\circ}$ CMEMS state estimate is already fully spun-up and the growth timescale of mixed layer submesoscale eddies is $\mathscr{O}(1)$ day (e.g. Fox-Kemper et al. 2008), this is sufficient spin-up time for both the submesoscale and mesoscale kinetic energy fields to saturate (not shown).

The open boundary conditions for these simulations are provided from the daily snapshots of the $1 / 24^{\circ}$ simulation. Each simulation in the nesting hierarchy is initialized using the model state of the simulation one level coarser and after one day of simulated time, e.g. the $1 / 24^{\circ}$ is initialized on 24 April using the solution of the $1 / 12^{\circ}$ simulation, and so on. This allows the model to adjust to each new resolution and reduces spurious numerical artifacts which may arise from the interpolation. The choice to double the grid resolution at each level of the nesting procedure was made to minimize the risk that these numerical artifacts would crash the model. While it is possible that larger jumps in resolution could have been taken without inducing a model crash, limited computing resources prevented exploration of more aggressive downscaling procedures. The analysis in this manuscript will primarily use output from the highest-resolution, $1 / 192^{\circ}$, simulation and will focus on dynamics in the surface boundary layer. Surface fields from this simulation are saved as hourly averages, and full 3D fields are saved as daily averages. The horizontal resolution is anisotropic and varies with latitude, but remains between 290 and $380 \mathrm{~m}$ 
in the zonal direction in this simulation. The meridional resolution is fixed at around $590 \mathrm{~m}$. This simulation is four times higher resolution than the simulations of Rocha et al. (2016), which were also run for the Drake Passage region, and thus permits more small-scale variability, though unlike Rocha et al. (2016) these simulations do not include tidal forcing. The resolution of this simulation is expected to fully resolve submesoscale mixed layer baroclinic eddies (hereafter MLE).

The $1 / 192^{\circ}$ simulation is able to successfully capture key features of the circulation in and around the Scotia Sea region (e.g. Sokolov and Rintoul 2009). Flow along the ACC has a strong barotropic component, is predominantly zonal, and consists of several jets with speeds $>1 \mathrm{~m} \mathrm{~s}^{-1}$. The Subantarctic and Polar Fronts are located close together in the Drake Passage constriction. These fronts separate just east of Burdwood Bank $\left(54^{\circ} \mathrm{W}\right)$ where the Subantarctic Front is redirected north to connect with the Malvinas Current (Figure 1). Mesoscale meanders and eddies develop south of the Scotia Ridge in the Scotia Sea, a region characterized as an eddy "hot spot" (Frenger et al. 2015). The time-averaged eddy kinetic energy from the model ranges from $10^{-2}$ to $10^{-1} \mathrm{~m}^{2} \mathrm{~s}^{-2}$ (Figure 4), in agreement with EKE estimates calculated from altimetry-derived geostrophic surface currents (AVISO; 1993-2015).

\section{Results}

Due to the variability in the $1 / 192^{\circ}$ simulation on small spatial and fast time scales, further averaging is performed as part of the analysis. Following the notation of Rosso et al. (2015), temporal means will be denoted by an overbar $\left(^{-}\right)$and are performed over the month of June 2015 , and angle brackets $\langle\cdot\rangle$ indicate a spatial average. The fluctuating part of the flow is defined as the departure from the time mean. The mesoscale component, denoted with subscript ${ }_{M}$, is obtained by applying a $2 \mathrm{D}$ convolution filter of width $32 \Delta x$, or $1 / 6^{\circ}$, to the fluctuations. This filter width, which is about $16 \mathrm{~km}$, is chosen because it lies at the approximate cutoff between mesoscales, 
whose characteristic horizontal length scales are 10-100 km, and submesoscales, which occupy the range of $1-10 \mathrm{~km}$ (e.g. Thomas et al. 2008). The submesoscale component, denoted with subscript $s$, is the residual between the unfiltered fluctuations and the mesoscale fields, and includes all dynamics smaller than the filter width.

\section{a. Change in mixed layer depth and vertical velocity}

The effects of downscaling from mesoscale-permitting to submesoscale-permitting resolution have been explored in previous studies comparing model dynamics at multiple scales (e.g. Capet et al. 2008a,b,c; Rosso et al. 2014, 2015, 2016), which is most readily seen in the appearance of MLE. MLE are energised by converting potential energy into kinetic energy, and in doing so tilt density surfaces toward the horizontal and increase the mixed layer stratification (e.g. Boccaletti et al. 2007; Fox-Kemper et al. 2008). Here we will define the mixed layer depth $H_{M L}$ to be the shallowest depth where the change in density $\Delta \rho=\left.\rho\right|_{z}-\left.\rho\right|_{z=0}>0.03 \mathrm{~kg} \mathrm{~m}^{-3}$ (de Boyer Montégut et al. 2004). Because the effects of MLE lead to a higher rate of change in the density with depth, they can also result in a shallower mixed layer depth.

Figure 2a shows $\overline{H_{M L}}$ from the $1 / 192^{\circ}$ simulation, which exhibits significant variability in both magnitude and spatial distribution. The range of $\overline{H_{M L}}$ observed in the Drake Passage tends to remain between 75 and $250 \mathrm{~m}$, broadly in agreement with Argo climatology of mixed layer depths for this region at the onset of the Southern Hemisphere winter (e.g. Dong et al. 2008; Holte and Talley 2009). The model $\overline{H_{M L}}$ field exhibits sharp meridional gradients in comparison with the Argo climatology, likely due both to the high resolution of the model and the coarse mapping of float profiles in the climatology ( 2 degrees in latitude and 5 degrees in longitude).

The change in $\overline{H_{M L}}$ between the $1 / 12^{\circ}$ and $1 / 192^{\circ}$ simulations, $\Delta \overline{H_{M L}}$, is shown in Figure $2 \mathrm{~b}$, where positive values indicate a shallowing of the mixed layer depth with increasing resolution. 
As anticipated, $\overline{H_{M L}}$ indeed becomes shallower as the model resolution increases, but the change is greater in some regions than in others. In particular, in the westernmost region from $76^{\circ} \mathrm{W}$ to $72^{\circ} \mathrm{W}, \Delta \overline{H_{M L}}$ exceeds $100 \mathrm{~m}$ in places, as well as in a conspicuous jet-like feature extending from the tip of the continent at $55^{\circ} \mathrm{S}$. In contrast, the region east of $48^{\circ} \mathrm{W}$ shows almost no change in $\overline{H_{M L}}$ with increased resolution.

Submesoscale motions are also associated with a loss of balance and a corresponding increase in the strength of vertical circulations (e.g. Mahadevan and Tandon 2006; Capet et al. 2008b; Thomas et al. 2008; Klein and Lapeyre 2009). Modelling at higher resolution is expected to result in an increase in the root-mean square vertical velocity, $\overline{w_{r m s}}=\sqrt{\overline{w^{2}}}$, as smaller-scale processes become better resolved. Indeed, the $\overline{w_{r m s}}$ field from the $1 / 192^{\circ}$ simulation, shown in Figure $2 \mathrm{c}$, is significantly intensified in comparison with the lower resolution simulations (see also Figure 9 for numerical values). If submesoscale dynamics are indeed assumed to be the principal driver of the change in $\overline{H_{M L}}$ and increase in $\overline{w_{r m s}}$ between these models, this suggests some spatial inhomogeneity in the strength of the submesoscale eddy field. The nature of this inhomogeneity, and its implications for modelling of the ocean boundary layer, are investigated further on.

Also outlined in Figure 2 are the 400-m isobath (white line, panel (c)), and two regions, R1 and R2, which will be analysed in Section c. These regions are chosen because they exhibit the most extreme contrasts between their respective mesoscale and submesoscale motions, and the dynamical consequences of each. The 400-m isobath is chosen as a demarcation between the continental shelf, featuring $\mathscr{O}(1) \mathrm{km}$ eddies whose size is limited by the shallow depth (Figure 3a), and deep water. To enable a fair comparison between different regions, the analysis in this paper will only consider locations where the depth is greater than $400 \mathrm{~m}$. The $400-\mathrm{m}$ isobath and analysis regions are outlined on all subsequent Figures as a visual aid. 


\section{b. Submesoscale intensity varies spatially}

Submesoscale processes are associated with $\mathscr{O}(1)$ Rossby number (Thomas et al. 2008). One metric for the local submesoscale intensity could be the Rossby number $R o=|\zeta / f|$ based on the vertical component of the relative vorticity $\zeta=\partial v / \partial x-\partial u / \partial y$, where $(u, v)$ is the horizontal velocity and $f$ is the Coriolis parameter. While this definition of $R o$ can be straightforwardly calculated from the simulation data, this metric does not distinguish submesoscale features from strongly rotating mesoscale eddies or intense jets. Figure 3a shows a snapshot of $\zeta$ taken from June 30,2015 , where strongly rotating mesoscale eddies can easily be identified east of $56^{\circ} \mathrm{W}$.

To isolate submesoscale features from these larger structures we define the "mixed layer baroclinic" Rossby number, $R o_{b}=\left|\zeta_{b} / f\right|$, where $\zeta_{b}=\left.\zeta\right|_{z=0}-\left.\zeta\right|_{z=-400 m}$ is the difference in relative vorticity between the surface and a depth of $400 \mathrm{~m}$. This depth is chosen because it is well below the maximum $\overline{H_{M L}}$ of $221 \mathrm{~m}$ within the domain (Figure 2) and deeper than the continental shelf, so that statistics measured at this depth will be considered representative of the interior ocean in deep water. The expectation is that submesoscale features which are confined to the mixed layer will have large surface relative vorticity but small relative vorticity below the mixed layer. In constrast, features such as jets and mesoscale eddies which extend well below the mixed layer are expected to have similar relative vorticity at both depths, so $\zeta_{b}$ for these features will be small. Therefore, this definition is intended to distinguish mixed layer submesoscales from these other features. $R o_{b}$ is not calculated in regions where the ocean depth is less than $400 \mathrm{~m}$.

Figure $3 \mathrm{~b}$ shows $\overline{R o_{b}}$, where it is apparent that the mesoscale structures on the eastern side of the domain have been filtered out by the differencing operation. Values of $\overline{R o_{b}}$ near $\mathscr{O}(1)$ suggest higher activity of mixed layer submesoscales, whose location corresponds to the small vortical 
features seen on the southwest corner of Figure 3a. Regions where the depth is shallower than 400 $\mathrm{m}$ have been grayed out, and are excluded from the detailed analysis in Section c.

c. Correlation between mesoscales, submesoscales, $\overline{w_{r m s}}$, and $\Delta \overline{H_{M L}}$

Recent work by Rosso et al. (2015) employed a spatial filtering method to explore the relationship between vertical velocity and mesoscale eddy kinetic energy and strain in the Kerguelen Plateau region of the Southern Ocean. Following their approach, the kinetic energy associated with the mesoscale and submesoscale velocities can be defined $\frac{1}{2} \overline{\left|\mathbf{u}_{M}\right|^{2}}$ and $\frac{1}{2} \overline{\left|\mathbf{u}_{S}\right|^{2}}$, respectively. The mesoscale strain field can be diagnosed using the filtered velocity field as

$$
\overline{S_{M}}=\overline{\left[\left(\frac{\partial u_{M}}{\partial x}-\frac{\partial v_{M}}{\partial y}\right)^{2}+\left(\frac{\partial v_{M}}{\partial x}+\frac{\partial u_{M}}{\partial y}\right)^{2}\right]^{1 / 2}}
$$

Figure 4 shows the surface mesoscale and submesoscale kinetic energies and mesoscale strain.

The maps of $\Delta \overline{H_{M L}}, \overline{w_{r m s}}, \overline{R o_{b}}$, and the mesoscale fields in Figures 2 - 4 reveal an interesting spatial correlation between these quantities, where the largest vertical velocities are co-located with regions of high mesoscale $\mathrm{KE}$ and strain, and the largest values of $\Delta \overline{H_{M L}}$ occur where $\overline{R o_{b}}$ is largest. Both results taken individually are unsurprising. Strong vertical circulations can occur at mesoscale fronts (e.g. Nagai et al., 2006) and filaments (e.g. Lapeyre and Klein, 2006, McWilliams et al., 2014) in addition to being often associated with submesoscale dynamics. A large change in mixed layer depth can occur in regions of intense submesoscale activity due to the influence of MLE in restratifying the boundary layer. A surprising feature of these maps is the appearance of regions with large $\overline{w_{r m s}}$ and weak submesoscales with small $\overline{R o_{b}}$, the most notable of which are in and around $\mathrm{R} 2$, and regions of strong submesoscale activity with large $\overline{R o_{b}}$ and comparatively small $\overline{w_{r m s}}$, such as the area in and north of R1. 


\section{1) CoRrelations Within R1 AND R2}

In the previous figures two regions, R1 and R2 (Figure $2 b$ ), have been outlined which will be analysed further here. R1, which extends from $78^{\circ} \mathrm{W}$ to $72^{\circ} \mathrm{W}$ and $58^{\circ} \mathrm{S}$ to $55^{\circ} \mathrm{S}$, exhibits strong surface submesoscale activity as indicated by the maps of $\overline{R o_{b}}, \Delta \overline{H_{M L}}$, and submesoscale kinetic energy (Figure 4b), but relatively weak mesoscale flow (Figure 4a, c). R2 extends from $59^{\circ} \mathrm{W}$ to $48^{\circ} \mathrm{W}$ and $58^{\circ} \mathrm{S}$ to $55.5^{\circ} \mathrm{S}$ and features large $\overline{w_{r m s}}$, mesoscale kinetic energy, and mesoscale strain, but small $\overline{R o_{b}}$ and $\Delta \overline{H_{M L}}$. Note that the mean $\overline{H_{M L}}$ in both regions is similar (Figure 2a), despite significant local variations in $\mathrm{R} 1$.

The vertical profiles of $\overline{w_{r m s}}$ are consistent with the above interpretation of each region (Figure 5). For this analysis the vertical velocity field is filtered into mesoscale and submesoscale components before being squared and time-averaged, yielding ${\overline{\left(w_{r m s}\right)}}_{M}=\sqrt{\overline{w_{M}^{2}}}$ and $\overline{\left(w_{r m s}\right)_{S}}=\sqrt{\overline{w_{S}^{2}}}$. Vertical profiles of these fields are obtained by spatially averaging over R1 and R2, and are shown in Figure 5a and Figure 5b, respectively. The submesoscale component in R1 (red line, Figure 5a) features a local maximum in the mixed layer which extends down to $150 \mathrm{~m}$, the approximate mean mixed layer depth for this region (Figure 2a), suggesting the presence of intensified vertical motions from submesoscales in the mixed layer. The submesoscale component in R2 (red line, Figure 5b) has less surface intensification. Both mesoscale and submesoscale components increase with depth, with the submesoscale component being larger than the mesoscale component at nearly all depths. These results are consistent with those of Rosso et al. (2015, Figure 3), who attributed part of the submesoscale component at the surface and the bottom intensification to internal lee wave activity. To further justify this point, histograms of bathymetry (Figure 5; gray bars) show that the largest vertical velocities occur at or slightly above the bottom depths in both R1 and R2. 
The especially large velocities in R2 could also be partly due to the generation of lee waves from Drake Passage (e.g. Naveira Garabato et al. 2004; St. Laurent et al. 2012).

\section{2) CORRELATIONS OVER THE FULL DOMAIN}

Scatter plots can also be used to illustrate correlations between different variables in this analysis. Figure 6 shows how $\left\langle\overline{w_{r m s}}\right\rangle$ and $\left\langle\Delta \overline{H_{M L}}\right\rangle$ trend with $\left\langle\overline{R o_{b}}\right\rangle$, the mesoscale KE, and mesoscale strain over the full domain. In this analysis each field is averaged over $1^{\circ}$ boxes and includes only locations where the mean depth over these boxes exceeds $400 \mathrm{~m}$. Error bars are shown for each data point and represent one standard deviation above and below the mean for that box. The locations for each data point are indicated by color: blue dots indicate locations in R1, red dots indicate locations in R2, and gray dots indicate locations throughout the rest of the domain. A systematic increase in $\left\langle\overline{w_{r m s}}\right\rangle$ is observed at larger values of both mesoscale $\mathrm{KE}$ (panel (c), correlation coefficient $r=0.80$ ) and strain (panel (e), $r=0.73$ ). $\left\langle\overline{w_{r m s}}\right\rangle$ also trends positively with $\left\langle\overline{R o_{b}}\right\rangle$, consistent with submesoscale-driven vertical velocities. However, a second, sharper upward trend is evident near $\left\langle\overline{R o_{b}}\right\rangle=10^{-1}$, with vertical velocities approaching $100 \mathrm{~m}$ day $^{-1}$. These large vertical velocities and values of $\overline{R o_{b}} \sim 10^{-1}$ correspond to locations with large mesoscale KE and strain in R2. Due to the two competing trends, an overall weak correlation exists between $\left\langle\overline{w_{r m s}}\right\rangle$ and $\left\langle\overline{R o_{b}}\right\rangle$ (panel (a), $r=0.05$ ) across the domain. Conversely, $\left\langle\Delta \overline{H_{M L}}\right\rangle$ increases with $\left\langle\overline{R o_{b}}\right\rangle$ (panel (b), $r=0.64$ ) but shows no clear trend with either the mesoscale KE (panel (d), $r=-0.12$ ) or strain (panel (f), $r=0.20)$.

A full list of the correlation coefficients between $\left\langle\overline{w_{r m s}}\right\rangle,\left\langle\Delta \overline{H_{M L}}\right\rangle$, and each of these variables appears in Table 1. In this Table different regions are indicated by font style, with boldface font indicating values over the whole domain, standard font values for R1, and italic font values for R2. The correlation coefficients tend to be consistent from region to region for strongly corre- 
lated variables, whereas the coefficients for weakly correlated variables tend to have much more variation.

Due to the occurrence of many submesoscale instabilities at mixed layer fronts, extant submesoscale parameterizations have been designed to be sensitive to the frontal strength, $\left|\nabla_{h} b\right|$ (e.g. Fox-Kemper et al. 2008; Canuto and Dubovikov 2010; Bachman et al. 2017), where $\nabla_{h}$ is the horizontal gradient operator and $b$ is the buoyancy. Maps of the frontal strength from both the $1 / 12^{\circ}$ and $1 / 192^{\circ}$ simulations are shown in Figure 7 (top row). The spatial pattern of the frontal strength qualitatively matches that of the change in mixed layer depth, $\overline{\Delta H_{M L}}$, between simulations (Figure 2b). The higher resolution model permits tighter fronts to form, reflected in a tendency for $\overline{\left|\nabla_{h} b\right|}$ to be larger almost everywhere in the $1 / 192^{\circ}$ simulation. When $\overline{\nabla_{h} b \mid}$ from these simulations is coarse-grained over $1^{\circ}$ boxes a positive correlation is evident between $\left\langle\overline{\Delta H_{M L}}\right\rangle$ and $\left\langle\overline{\left|\nabla_{h} b\right|}\right\rangle$ in both the $1 / 12^{\circ}(r=0.58)$ and $1 / 192^{\circ}(r=0.66)$ models (Figure 7 , bottom row). The correlation between $\left\langle\overline{\left|\nabla_{h} b\right|}\right\rangle$ and $\left\langle\overline{w_{r m s}}\right\rangle$ is weak ( $r=-0.18$ for both models), as is the direct correlation between $\left\langle\overline{\Delta H_{M L}}\right\rangle$ and $\left\langle\overline{w_{r m s}}\right\rangle\left(r=0.08\right.$ for the $1 / 12^{\circ}$ model; $r=0.07$ for the $1 / 192^{\circ}$ model; not shown).

\section{d. A possible mechanism for large $\overline{w_{r m s}}$}

A question remains about how to physically interpret the large $\overline{w_{r m s}}$ in $\mathrm{R} 2$ if it is not associated with submesoscale circulations. Bottom intensification of the vertical velocity due to topography can explain the large velocities below $3000 \mathrm{~m}$, and the region is known to be a hotspot for lee wave generation (Watson et al. 2013). Rosso et al. (2015) found that such bottom-generated internal waves only occasionally reached the mid- to upper ocean, however, and that the dominant temporal frequency of the submesoscale vertical velocity was much slower than could be explained by 
internal wave activity. A local maximum in $\overline{w_{r m s}}$ shallower than $500 \mathrm{~m}$ depth in $\mathrm{R} 2$ also suggests a surface-intensified generation mechanism (Figure 5b).

Rocha et al. (2016) calculated horizontal wavenumber spectra in Drake Passage and found that ageostrophic motions in this region are likely dominated by internal waves, which imprint strongly on the near-surface kinetic energy at scales between 10 and $40 \mathrm{~km}$ and might explain the strong velocities in R2. A possible source of these waves was explored by Shakespeare and Hogg (2017), who highlighted the process of wave generation through frontogenesis in the Southern Ocean. Recent studies by Shakespeare and Taylor $(2014,2015,2016)$ focused on wave generation and dynamics of the ageostrophic secondary circulation which develops at fronts undergoing large strain (up to $\mathscr{O}(f)$ ), and have led to a theoretical scaling for the vertical velocity associated with these fronts (Shakespeare 2015; Shakespeare and Taylor 2016),

$$
W \sim H \zeta\left(1+\frac{\zeta}{f}\right) \frac{S}{f^{2}}\left(f^{2}+S^{2}\right)^{1 / 2}
$$

This scaling is a function of a depth scale, $H$, Coriolis parameter, $f$, large-scale relative vorticity, $\zeta$, and large-scale strain, $S$. Here we compare this scaling to the simulated flow by using the mixed layer depth $\overline{H_{M L}}$ as the depth scale, a low-pass filtered $\overline{\zeta_{M}}$ as the large-scale relative vorticity, and $\overline{S_{M}}$ as the large scale strain. The map of $W$ using these diagnosed parameters and a proportionality coefficient of 1.5 is shown in Figure 8a. Comparing against the map of $\overline{w_{r m s}}$ in Figure 8b, the scaling is a good approximation to the diagnosed $\overline{w_{r m s}}$ throughout the domain. The scaling is less skillful in the boundary current around the edge of the continent and on the continental shelf, but it is unclear whether $H_{M L}$ and mesoscale parameters are appropriate in these shallow regions. These areas lie within the $400 \mathrm{~m}$ isobath (white line) and will not be considered further. Figure $8 \mathrm{c}$ shows 
a scatter plot of the $1^{\circ}$-averaged $\left\langle\overline{w_{r m s}}\right\rangle$ against $\langle W\rangle$. The scaling shows good agreement $(r=0.78)$ with the diagnosed $\left\langle\overline{w_{r m s}}\right\rangle$ across over an order of magnitude.

\section{e. Sensitivity of $\left\langle\overline{w_{r m s}}\right\rangle$ to grid resolution}

The simulation results and comparison against theory suggest frontogenesis and complex bottom topography as two mechanisms responsible for large $\left\langle\overline{w_{r m s}}\right\rangle$ in the Scotia Sea region. Because both the mesoscale strain field (Figure 4c) and bottom topography are highly variable in this region, it is likely that the magnitude of $\left\langle\overline{w_{r m s}}\right\rangle$ would vary significantly over the rest of the Southern Ocean as well.

Very few modelling studies have been conducted at sufficient resolution to capture mesoscale, submesoscale, and topographic interactions, particularly with regard to wave-driven vertical motions. Due to the important role waves play in exchanging energy with the large-scale flow at rough topography (e.g. Nikurashin and Ferrari 2010a,b, 2011) and driving mixing in the deep ocean (Wunsch and Ferrari 2004), such studies are needed to fill gaps in our understanding of how the energy of the general circulation is dissipated. From an ocean modelling perspective, these studies are needed to assess and accurately estimate dissipation due to unresolved wave generation and breaking. The simulations used here offer a unique opportunity to explore these multi-scale interactions because they are run at five different horizontal resolutions, spanning from a mesoscalepermitting regime with no submesoscales in the $1 / 12^{\circ}$ model, to a submesoscale-resolving regime with significant wave activity in the $1 / 192^{\circ}$ model.

Previous studies using high-resolution numerical simulations have found varying sensitivity of $\left\langle\overline{w_{r m s}}\right\rangle$ to changing the horizontal resolution. This sensitivity can be straightforwardly quantified by defining an enhancement factor, 


$$
s=\frac{\text { Fractional change in }\left\langle\overline{w_{r m s}}\right\rangle}{\text { Fractional change in resolution }} .
$$

The realistic simulations of Rosso et al. (2014) and Capet et al. (2008a) found $s=2.75$ and $s=2.5$, respectively, which were much higher than $s=0.57$ and $s=0.2$ found by Lévy et al. (2001) and Lévy et al. (2012). The latter two simulations were run using an idealised, flat-bottom domain, however, implicating bottom topography as the reason for the pronounced difference in $s$ between these studies.

Because each model in our nesting hierarchy is exactly twice the resolution of the previous model, we are able to calculate $s$ as a function of resolution as well. Figure 9 shows how $\left\langle\overline{w_{r m s}}\right\rangle$ is enhanced by increased resolution, where the $\overline{w_{r m s}}$ fields are averaged vertically over the top $400 \mathrm{~m}$ and horizontally over (a) R1, (b) R2, and (c) the whole domain. As expected, the values of $\left\langle\overline{w_{r m s}}\right\rangle$ monotonically increase with resolution, although $s$ is dependent on both resolution and location. The values of $s$ stay relatively consistent in R1, remaining between 1.1 and 1.4 each time the resolution is doubled. This is the same magnitude of increase seen in R2 and over the whole domain when the resolution is increased to $1 / 24^{\circ}$ and $1 / 48^{\circ}$. However, $s$ increases noticeably each time when downscaling to $1 / 96^{\circ}$ and $1 / 192^{\circ}$.

We hypothesize that the lower values of $s$ up to $1 / 48^{\circ}$ occur because the resolved mesoscale dynamics are relatively unchanged by downscaling between the $1 / 12^{\circ}$ and $1 / 48^{\circ}$ models. That is, the eddying flow up to this resolution is driven primarily by baroclinic turbulence, while smaller submesoscale instabilities, convection, and waves remain unresolved. The emergence of submesoscale dynamics and some internal wave activity causes a jump in $s$ at $1 / 96^{\circ}$, which is further accentuated by a vigorous internal wave field appearing at $1 / 192^{\circ}$, particularly in R2. Interestingly, spatial inhomogeneity also begins to emerge at these high resolutions, as reflected by the 
sharp increase in $s$ in R2 compared with R1. Counterintuitively, it is R2 that is responsible for the largest value, $s=2.4$, at $1 / 192^{\circ}$.

\section{Conclusions}

In this study a series of numerical simulations of the Scotia Sea region have been used to investigate the effects of mesoscale and submesoscale processes on the oceanic surface boundary layer. The highest-resolution member of the series has a grid spacing of about $500 \mathrm{~m}$ and is capable of resolving submesoscale dynamics, enabling an analysis of the oceanic boundary layer which is not possible using coarser models. The "baroclinic Rossby number", $R o_{b}$, defined as the difference in relative vorticity between the surface and the interior, has been used to identify regions of mixed layer submesoscale activity. A comparison of the highest-resolution model against the lowest-resolution model, which has a resolution of about $8 \mathrm{~km}$ and therefore is unable to resolve any submesoscales, shows significant differences in many key metrics, including relative vorticity, frontal strength, mixed layer depth, RMS vertical velocity, and kinetic energy.

Here we have highlighted differences in the time-averaged mixed layer depth, $\Delta \overline{H_{M L}}$, and RMS vertical velocity, $\overline{w_{r m s}}$, between the low- and high-resolution models because these metrics are especially significant to the ocean's role in affecting climate. Ocean-atmosphere exchange is modulated by the character of the mixed layer, with the mixed layer depth affecting the ocean's ability to uptake and store heat and trace gases on short timescales. These air-sea interactions are especially important in the Southern Ocean, which is a key region for anthropogenic carbon uptake (Khatiwala et al. 2009; Sallée et al. 2012; Frölicher et al. 2015) through the subduction of mode and intermediate waters. Large, persistent vertical velocity can transport tracers between the mixed layer and the ocean interior where it can be stored on long timescales, and is also an indicator of nutrient supply for phytoplankton growth (e.g. Lévy et al. 2001). These metrics are expected to be 
particularly sensitive to model resolution between the meso- and submesoscales, where dynamics become less constrained by the Earth's rotation and vertical transport is enhanced. Understanding how the mixed layer responds to dynamics at multiple scales is therefore crucial to our ability to predict the future climate, making the models in this study especially useful in this regard.

Previous work by Rosso et al. (2015) used a submesoscale-resolving model to establish a relationship between regions of large submesoscale vertical velocity, $\overline{\left|w_{S}\right|}$, and mesoscale kinetic energy and strain, treating $\overline{\left|w_{S}\right|}$ as a proxy for near-surface submesoscale activity. However, $\overline{\left|w_{S}\right|}$ does not distinguish between small-scale processes like internal waves which can drive strong vertical motions, and the more climatically relevant mixed layer submesoscales which modulate air-sea exchange. In this work we take a slightly different approach, which is to first identify regions of mixed layer submesoscale activity using maps of $\overline{R o_{b}}$ before performing analysis of $\overline{w_{r m s}}$. In agreement with Rosso et al. (2015), we find that submesoscales are associated with enhanced $\overline{w_{r m s}}$, but also find an even larger enhancement of $\overline{w_{r m s}}$ which may be due to mesoscale frontogenesis (e.g. Shakespeare and Taylor 2014). We also find a close link between regions of enhanced $\overline{R o_{b}}$ and large $\Delta \overline{H_{M L}}$, the latter of which is likely caused by resolving mixed layer baroclinic instability.

These results suggest a similar but nuanced interpretation relative to that of Rosso et al. (2015). Submesoscales are coincident with strong vertical velocities, but regions of strong vertical velocity should not necessarily be used as an indicator of enhanced mixed layer submesoscale activity. Mesoscale frontogenesis is suggested as a mechanism leading to large vertical velocity in certain regions where submesoscales are not necessarily present, and the magnitude of this velocity can exceed that associated with submesoscales. However, the regions of large vertical velocity are not always associated with a shallowing of the mixed layer depth. The interpretation of these results has significant consequences for the development of deterministic submesoscale eddy parameterizations, whose effects are sensitive to the mesoscale flow. Our results indicate no systematic rela- 
tionship between mesoscale kinetic energy and strain and $\Delta \overline{H_{M L}}$, raising questions about whether these fields are appropriate to inform an eddy parameterization (e.g. Rosso et al. 2015). We find a stronger correlation between $\Delta \overline{H_{M L}}$ and the coarse-resolution lateral density gradient, the latter of which is already used as the basis for multiple submesoscale eddy closures (Fox-Kemper et al. 2008; Bachman et al. 2017).

Internal waves act as a primary pathway toward energy dissipation and play a key role in driving mixing in the deep ocean (Wunsch and Ferrari 2004; Ferrari and Wunsch 2009). Much of this mixing and dissipation is due to wave breaking, a process which is parameterized in hydrostatic models by the use of vertical eddy viscosity but could be explicitly resolved upon moving to nonhydrostatic modelling. The richness of the internal wave field in the $1 / 192^{\circ}$ simulation suggests that it lies close to the resolution threshold where a nonhydrostatic model would be appropriate. The nonhydrostatic parameter (Marshall et al. 1997b), $\eta=h^{2} /\left(L^{2} R i\right)$, can be used as a gauge of whether a nonhydrostatic model is necessary, where $h$ and $L$ are characteristic depth and horizontal length scales, and the Richardson number, $R i=N^{2} h^{2} / U^{2}$, is a function of the buoyancy frequency, $N$, and characteristic velocity scale, $U$. This parameter is likely to be largest in the mixed layer where $R i$ is small and the aspect ratio, $h / L$, is large. Using values from the $1 / 192^{\circ}$ simulation, where $h=100 \mathrm{~m}$ is an approximate mixed layer depth, $L=\Delta x=500 \mathrm{~m}$ is an average grid spacing, and $R i=1$ for the mixed layer (e.g. Young 1994; Thomas et al. 2008; Bachman and Taylor 2016), we have $\eta=1 / 25<<1$, so that motion is approximately hydrostatic. It is possible that another downscaling to $1 / 384^{\circ}$ would require a nonhydrostatic model; however, because the computational burden of nonhydrostatic models is significantly higher, this realm of modelling tends to remain out of reach for regional studies such as those presented here.

The Southern Ocean has several characteristics, such as weak vertical stratification in the upper ocean, strong mesoscale kinetic energy, and significant eddy-mean flow interaction (e.g. 
Naveira Garabato et al. 2011), and further research is required to understand whether the correlations and localized submesoscale activity we find in the Scotia Sea region occur in the rest of the ocean as well. Our simulations indicate that submesoscales are spatially variable and can be highly active immediately adjacent to a region where they are nearly absent. It is unclear what causes this spatial inhomogeneity, especially given that the regions of highest mesoscale strain, where we would expect submesoscale-generating mechanisms like frontogenesis (Thomas and Ferrari 2008) and frontal instabilities (Mahadevan and Tandon 2006; Thomas et al. 2008) to be prevalent, are not always associated with elevated submesoscale activity. Further research is necessary to determine the causes and consequences of this observation, and is ongoing.

Acknowledgments. The authors gratefully acknowledge support from the Natural Environment Research Council, awards NE/J010472/1 and NE/J009857/1. This work used the ARCHER UK National Supercomputing Service (http://www.archer.ac.uk). Discussions and advice from Dave Munday about how to configure the simulations were extremely helpful. The altimeter products were produced by Ssalto/Duacs and distributed by Aviso, with support from Cnes (http://www.aviso.altimetry.fr/duacs/).

\section{References}

Adams, K., P. Hosegood, J. Taylor, J.-B. Sallée, S. Bachman, and M. Stamper, 2017: Frontal circulation and submesoscale variability during the formation of a Southern Ocean mesoscale eddy. Journal of Physical Oceanography, Accepted for publication.

Bachman, S., B. Fox-Kemper, J. Taylor, and L. Thomas, 2017: Parameterization of frontal symmetric instabilities. I: Theory for resolved fronts. Ocean Modelling, 109(1), 72-95, doi: 10.1016/j.ocemod.2016.12.003. 
Bachman, S., and J. Taylor, 2016: Numerical simulations of the equilibrium between eddy-induced restratification and vertical mixing. Journal of Physical Oceanography, 46 (3), 919-935, doi: 10.1175/JPO-D-15-0110.1.

Boccaletti, G., R. Ferrari, and B. Fox-Kemper, 2007: Mixed layer instabilities and restratification. Journal of Physical Oceanography, 37(9), 2228-2250, doi:10.1175/JPO3101.1.

Brannigan, L., D. Marshall, A. Naveira Garabato, and A. Nurser, 2015: The seasonal cycle of submesoscale flows. Ocean Modelling, 92, 69-84, doi:10.1016/j.ocemod.2015.05.002.

Buckingham, C., and Coauthors, 2016: Seasonality of submesoscale flows in the ocean surface boundary layer. Geophysical Research Letters, 43(5), 2118-2126, doi:10.1002/2016GL068009.

Callies, J., R. Ferrari, J. Klymak, and J. Gula, 2015: Seasonality in submesoscale turbulence. Nature Communications, 6:6862, doi:10.1038/ncomms7862.

Canuto, V., and M. Dubovikov, 2010: Mixed layer sub-mesoscale parameterization - part 1: Derivation and assessment. Ocean Science, 6 (3), 679-693, doi:10.5194/os-6-679-2010.

Capet, X., J. McWilliams, M. Molemaker, and A. Shchepetkin, 2008a: Mesoscale to submesoscale transition in the California Current system. Part I: Flow structure, eddy flux, and observational tests. Journal of Physical Oceanography, 38(1), 29-43, doi:10.1175/2007JPO3671.1.

Capet, X., J. McWilliams, M. Molemaker, and A. Shchepetkin, 2008b: Mesoscale to submesoscale transition in the California Current system. Part II: Frontal processes. Journal of Physical Oceanography, 38(1), 44-64, doi:10.1175/2007JPO3672.1.

Capet, X., J. McWilliams, M. Molemaker, and A. Shchepetkin, 2008c: Mesoscale to submesoscale transition in the California Current system. Part III: Energy balance and flux. Journal of Physical Oceanography, 38(10), 2256-2269, doi:10.1175/2008JPO3810.1. 
Cerovečki, I., L. Talley, M. Mazloff, and G. Maze, 2013: Subantarctic Mode Water formation, destruction, and export in the eddy-permitting Southern Ocean state estimate. Journal of Physical Oceanography, 43(7), 1485-1511, doi:10.1175/JPO-D-12-0121.1.

Chassignet, E., and Z. Garraffo, 2001: Viscosity parameterization and the Gulf Stream separation. Proceedings of the 'Aha Huliko'a Hawaiian Winter Workshop, University of Hawaii at Manoa, Honolulu, Hawaii, 37-41.

D’Asaro, E., C. Lee, L. Rainville, R. Harcourt, and L. Thomas, 2011: Enhanced turbulence and energy dissipation at ocean fronts. Science, 332(6027), 318-322, doi:10.1126/science.1201515.

de Boyer Montégut, C., G. Madec, A. Fischer, A. Lazar, and D. Iudicone, 2004: Mixed layer depth over the global ocean: An examination of profile data and a profile-based climatology. Journal of Geophysical Research: Oceans, 109, C12 003, doi:10.1029/2004JC002378.

Dong, S., J. Sprintall, S. Gille, and L. Talley, 2008: Southern Ocean mixed-layer depth from argo float profiles. Journal of Geophysical Research: Oceans, 113 (C6), doi:10.1029/2006JC004051.

Ferrari, R., and C. Wunsch, 2009: Ocean circulation kinetic energy: Reservoirs, sources, and sinks. Annual Review of Fluid Mechanics, 41, 253-282, doi:10.1146/annurev.fluid.40.111406. 102139.

Flierl, G. R., and D. McGillicuddy, 2002: Mesoscale and submesoscale physical-biological interactions. The Sea, Vol. 12: Biological-Physical Interactions in the Sea, ed. by A. R. Robinson, J. J. McCarthy and B. J. Rothschild, Hoboken, NJ, 113-185.

Fox-Kemper, B., R. Ferrari, and R. Hallberg, 2008: Parameterization of mixed layer eddies. Part I: Theory and diagnosis. Journal of Physical Oceanography, 38(6), 1145-1165, doi:10.1175/ 2007JPO3792.1. 
Fox-Kemper, B., and D. Menemenlis, 2008: Can large eddy simulation techniques improve mesoscale rich ocean models? Geophysical Monograph Series, 177, 319-337, doi:10.1029/ $177 \mathrm{GM} 19$.

Frenger, I., M. Münnich, N. Gruber, and R. Knutti, 2015: Southern Ocean eddy phenomenology. Journal of Geophysical Research: Oceans, 120(11), 7413-7449, doi:10.1002/2015JC011047.

Frölicher, T., J. Sarmiento, D. Paynter, J. Dunne, J. Krasting, and M. Winton, 2015: Dominance of the Southern Ocean in anthropogenic carbon and heat uptake in CMIP5 models. Journal of Climate, 28 (2), 862-886.

Gargett, A., and J. Marra, 2002: Effects of upper ocean physical processes-turbulence, advection, and air-sea interaction-on oceanic primary production. The Sea, Vol. 12: Biological-Physical Interactions in the Sea, ed. by A. R. Robinson, J. J. McCarthy and B. J. Rothschild, Hoboken, NJ, 19-49.

Holte, J., and L. Talley, 2009: A new algorithm for finding mixed layer depths with applications to Argo data and Subantarctic Mode Water formation. Journal of Atmospheric and Oceanic Technology, 26 (9), 1920-1939, doi:10.1175/2009JTECHO543.1.

Jiao, Y., and W. Dewar, 2015: The energetics of centrifugal instability. Journal of Physical Oceanography, 45 (6), 1554-1573.

Khatiwala, S., F. Primeau, and T. Hall, 2009: Reconstruction of the history of anthropogenic CO2 concentrations in the ocean. Nature, 462(7271), 346-349, doi:10.1038/nature08526.

Klein, P., and G. Lapeyre, 2009: The oceanic vertical pump induced by mesoscale and submesoscale turbulence. Annual Review of Marine Science, 1, 351-375, doi:10.1146/annurev.marine. 010908.163704 . 
Klocker, A., and R. Abernathey, 2014: Global patterns of mesoscale eddy properties and diffusivities. Journal of Physical Oceanography, 44(3), 1030-1046, doi:10.1175/JPO-D-13-0159.1.

Lapeyre, G., and P. Klein, 2006: Dynamics of the upper oceanic layers in terms of surface quasigeostrophy theory. Journal of Physical Oceanography, 36(2), 165-176, doi:10.1175/JPO2840. 1.

Large, W., J. McWilliams, and S. Doney, 1994: Oceanic vertical mixing: A review and a model with a nonlocal boundary layer parameterization. Reviews of Geophysics, 32 (4), 363-403, doi: 10.1029/94RG01872.

Leith, C., 1996: Stochastic models of chaotic systems. Physica D: Nonlinear Phenomena, 98(2), 481-491, doi:10.1016/0167-2789(96)00107-8.

Lévy, M., D. Iovino, L. Resplandy, P. Klein, G. Madec, A. Tréguier, S. Masson, and K. Takahashi, 2012: Large-scale impacts of submesoscale dynamics on phytoplankton: Local and remote effects. Ocean Modelling, 43, 77-93, doi:10.1016/j.ocemod.2011.12.003.

Lévy, M., P. Klein, and A. Tréguier, 2001: Impact of sub-mesoscale physics on production and subduction of phytoplankton in an oligotrophic regime. Journal of Marine Research, 59(4), 535-565, doi:10.1357/002224001762842181.

Lévy, M., and A. Martin, 2013: The influence of mesoscale and submesoscale heterogeneity on ocean biogeochemical reactions. Global Biogeochemical Cycles, 27(4), 1139-1150, doi: $10.1002 / 2012 \mathrm{~GB} 004518$.

Mahadevan, A., and D. Archer, 2000: Modeling the impact of fronts and mesoscale circulation on the nutrient supply and biogeochemistry of the upper ocean. Journal of Geophysical Research: Oceans, 105, 1209-1225, doi:10.1029/1999JC900216. 
Mahadevan, A., and A. Tandon, 2006: An analysis of mechanisms for submesoscale vertical motion at ocean fronts. Ocean Modelling, 14(3), 241-256, doi:10.1016/j.ocemod.2006.05.006.

Marshall, J., A. Adcroft, C. Hill, L. Perelman, and C. Heisey, 1997a: A finite-volume, incompressible Navier-Stokes model for studies of the ocean on parallel computers. Journal of Geophysical Research: Oceans, 102(C3), 5753-5766, doi:10.1029/96JC02775.

Marshall, J., C. Hill, L. Perelman, and A. Adcroft, 1997b: Hydrostatic, quasi-hydrostatic, and nonhydrostatic ocean modeling. Journal of Geophysical Research: Oceans, 102 (C3), 57335752, doi:10.1029/96JC02776.

McWilliams, J., J. Molemaker, and I. Yavneh, 2001: From stirring to mixing of momentum: Cascades from balanced flows to dissipation in the oceanic interior. Proceedings of the 'Aha $\mathrm{Hu}$ liko'a Hawaiian Winter Workshop, University of Hawaii at Manoa, Honolulu, Hawaii, 59-66.

Mensa, J., Z. Garraffo, A. Griffa, T. Özgökmen, A. Haza, and M. Veneziani, 2013: Seasonality of the submesoscale dynamics in the Gulf Stream region. Ocean Dynamics, 63(8), 923-941, doi:10.1007/s10236-013-0633-1.

Molemaker, M., J. McWilliams, and I. Yavneh, 2005: Baroclinic instability and loss of balance. Journal of Physical Oceanography, 35(9), 1505-1517, doi:10.1175/JPO2770.1.

Naveira Garabato, A., R. Ferrari, and K. Polzin, 2011: Eddy stirring in the Southern Ocean. Journal of Geophysical Research: Oceans, 116(C09019), doi:10.1029/2010JC006818.

Naveira Garabato, A., K. Polzin, B. King, K. Heywood, and M. Visbeck, 2004: Widespread intense turbulent mixing in the Southern Ocean. Science, 303(5655), 210-213, doi:10.1126/ science.1090929. 
Nikurashin, M., and R. Ferrari, 2010a: Radiation and dissipation of internal waves generated by geostrophic motions impinging on small-scale topography: Application to the Southern Ocean. Journal of Physical Oceanography, 40(9), 2025-2042, doi:10.1175/2010JPO4315.1.

Nikurashin, M., and R. Ferrari, 2010b: Radiation and dissipation of internal waves generated by geostrophic motions impinging on small-scale topography: Theory. Journal of Physical Oceanography, 40(5), 1055-1074, doi:10.1175/2009JPO4199.1.

Nikurashin, M., and R. Ferrari, 2011: Global energy conversion rate from geostrophic flows into internal lee waves in the deep ocean. Geophysical Research Letters, 38(8), L08610, doi:10. 1029/2011GL046576.

Omand, M., E. D’Asaro, C. Lee, M. Perry, N. Briggs, I. Cetinić, and A. Mahadevan, 2015: Eddy-driven subduction exports particulate organic carbon from the spring bloom. Science, 348(6231), 222-225, doi:10.1126/science.1260062.

Pollard, R., and L. Regier, 1990: Large variations in potential vorticity at small spatial scales in the upper ocean. Nature, 348(6298), 227-229, doi:10.1038/348227a0.

Rocha, C., T. Chereskin, S. Gille, and D. Menemenlis, 2016: Mesoscale to submesoscale wavenumber spectra in Drake Passage. Journal of Physical Oceanography, 46(2), 601-620, doi:10.1175/JPO-D-15-0087.1.

Rosso, I., A. Hogg, A. Kiss, and B. Gayen, 2015: Topographic influence on submesoscale dynamics in the Southern Ocean. Geophysical Research Letters, 42(4), 1139-1147, doi: 10.1002/2014GL062720. 
Rosso, I., A. Hogg, R. Matear, and P. Strutton, 2016: Quantifying the influence of sub-mesoscale dynamics on the supply of iron to Southern Ocean phytoplankton blooms. Deep Sea Research Part I: Oceanographic Research Papers, 115, 199-209, doi:10.1016/j.dsr.2016.06.009.

Rosso, I., A. Hogg, P. Strutton, A. Kiss, R. Matear, A. Klocker, and E. van Sebille, 2014: Vertical transport in the ocean due to sub-mesoscale structures: Impacts in the Kerguelen region. Ocean Modelling, 80, 10-23, doi:10.1016/j.ocemod.2014.05.001.

Rudnick, D., 1996: Intensive surveys of the Azores Front: 2. Inferring the geostrophic and vertical velocity fields. Journal of Geophysical Research: Oceans, 101(C7), 16291-16303, doi:10. 1029/96JC01144.

Sallée, J.-B., R. Matear, S. Rintoul, and A. Lenton, 2012: Localized subduction of anthropogenic carbon dioxide in the Southern Hemisphere oceans. Nature Geoscience, 5 (8), 579-584, doi: 10.1038/ngeo1523.

Sallée, J.-B., K. Speer, and R. Morrow, 2008: Response of the Antarctic Circumpolar Current to atmospheric variability. Journal of Climate, 21(12), 3020-3039, doi:10.1175/2007JCLI1702.1.

Sallée, J.-B., K. Speer, S. Rintoul, and S. Wijffels, 2010: Southern Ocean thermocline ventilation. Journal of Physical Oceanography, 40(3), 509-529, doi:10.1175/2009JPO4291.1.

Sasaki, H., P. Klein, B. Qiu, and Y. Sasai, 2014: Impact of oceanic-scale interactions on the seasonal modulation of ocean dynamics by the atmosphere. Nature Communcations, 5, 5636, doi:10.1038/ncomms6636.

Shakespeare, C., 2015: On the generation of waves during frontogenesis. Doctoral dissertation, University of Cambridge, Cambridge, UK. 
Shakespeare, C., and A. Hogg, 2017: Spontaneous surface generation and interior amplification of internal waves in a regional-scale ocean model. Journal of Physical Oceanography, 47(4), 811-826, doi:10.1175/JPO-D-16-0188.1.

Shakespeare, C., and J. Taylor, 2014: The spontaneous generation of inertia-gravity waves generated during frontogenesis forced by large strain: Theory. Journal of Fluid Mechanics, 757, 817-853, doi:10.1017/jfm.2014.514.

Shakespeare, C., and J. Taylor, 2015: The spontaneous generation of inertia-gravity waves generated during frontogenesis forced by large strain: Numerical simulations. Journal of Fluid Mechanics, 772, 508-534, doi:10.1017/jfm.2015.197.

Shakespeare, C., and J. Taylor, 2016: Spontaneous wave generation at strongly strained density fronts. Journal of Physical Oceanography, 46(7), 2063-2081, doi:10.1175/JPO-D-15-0043.1.

Sokolov, S., and S. Rintoul, 2009: Circumpolar structure and distribution of the Antarctic Circumpolar Current fronts: 1. Mean circumpolar paths. Journal of Geophysical Research: Oceans, 114 (C11), doi:10.1029/2008JC005108.

Spall, S., and K. Richards, 2000: A numerical model of mesoscale frontal instabilities and plankton dynamics - I. Model formulation and initial experiments. Deep Sea Research Part I: Oceanographic Research Papers, 47(7), 1261-1301, doi:10.1016/S0967-0637(99)00081-3.

St. Laurent, L., A. Naveira Garabato, J. Ledwell, A. Thurnherr, J. Toole, and A. Watson, 2012: Turbulence and diapycnal mixing in Drake Passage. Journal of Physical Oceanography, 42(12), 2143-2152, doi:10.1175/JPO-D-12-027.1.

Stone, P., 1966: On non-geostrophic baroclinic stability. Journal of the Atmospheric Sciences, 23(4), 390-400, doi:10.1175/1520-0469(1966)023<0390:ONGBS $\rangle 2.0 . C O ; 2$. 
Taylor, J. R., and R. Ferrari, 2009: On the equilibration of a symmetrically unstable front via a secondary shear instability. Journal of Fluid Mechanics, 622(1), 103-113, doi:10.1017/ S002211200800527.

Taylor, J. R., and R. Ferrari, 2010: Buoyancy and wind-driven convection at mixed layer density fronts. Journal of Physical Oceanography, 40(6), 1222-1242, doi:10.1175/2010JPO4365.1.

Thomas, L., 2005: Destruction of potential vorticity by winds. Journal of Physical Oceanography, 35(12), 2457-2466, doi:10.1175/JPO2830.1.

Thomas, L., and R. Ferrari, 2008: Friction, frontogenesis, and the stratification of the surface mixed layer. Journal of Physical Oceanography, 38(11), 2501-2518, doi:10.1175/ 2008JPO3797.1.

Thomas, L. N., A. Tandon, and A. Mahadevan, 2008: Submesoscale processes and dynamics. Ocean modeling in an eddying regime, 17-38, doi:10.1029/177GM04.

Thomas, L. N., and J. R. Taylor, 2010: Reduction of the usable wind-work on the general circulation by forced symmetric instability. Geophysical Research Letters, 37(18), L18 606, doi: 10.1029/2010GL044680.

Thompson, A., A. Lazar, C. Buckingham, A. Naveira Garabato, G. Damerell, and K. Heywood, 2016: Open-ocean submesoscale motions: A full seasonal cycle of mixed layer instabilities from gliders. Journal of Physical Oceanography, 46(4), 1285-1307, doi:10.1175/ JPO-D-15-0170.1.

Watson, A., J. Ledwell, M. Messias, B. King, N. Mackay, M. Meredith, B. Mills, and A. Garabato, 2013: Rapid cross-density ocean mixing at mid-depths in the Drake Passage measured by tracer release. Nature, 501(7467), 408-411, doi:10.1038/nature12432. 
Wunsch, C., and R. Ferrari, 2004: Vertical mixing, energy, and the general circulation of the oceans. Annual Review of Fluid Mechanics, 36, 281-314, doi:10.1146/annurev.fluid.36.050802. 122121.

Young, W., 1994: The subinertial mixed layer approximation. Journal of Physical Oceanography, 24 (8), 1812-1826, doi:10.1175/1520-0485(1994)024〈1812:TSMLA $\rangle 2.0 . C O ; 2$. 
${ }_{682}$ Table 1. Correlation coefficients between $\left\langle\overline{w_{r m s}}\right\rangle,\left\langle\Delta \overline{H_{M L}}\right\rangle$, and each of $\left\langle\overline{\operatorname{Ro}_{b}}\right\rangle,\left\langle\frac{1}{2} \overline{\mathbf{u}_{m}^{2}}\right\rangle$, $\left\langle\overline{S_{m}}\right\rangle$, and $\left\langle\overline{\left|\nabla_{h} b\right|}\right\rangle$ from the $1 / 192^{\circ}$ simulation. Regions are indicated by font style - boldface font indicates values measured over the whole domain, standard font indicates values measured only in R1, and italic font indicates values 


\begin{tabular}{|c|c|c|c|c|}
\hline & $\left\langle\overline{R o_{b}}\right\rangle$ & $\left\langle\frac{1}{2} \overline{\mathbf{u}_{m}^{2}}\right\rangle$ & $\left\langle\overline{S_{m}}\right\rangle$ & $\left\langle\overline{\left|\nabla_{h} b\right|}\right\rangle$ \\
\hline \multirow{4}{*}{$\left\langle\bar{w}_{r m s}\right\rangle$} & 0.05 & 0.80 & 0.73 & -0.18 \\
\hline & -0.32 & 0.64 & 0.57 & -0.52 \\
\hline & -0.21 & 0.81 & 0.72 & -0.58 \\
\hline & 0.64 & -0.12 & 0.20 & 0.66 \\
\hline \multirow[t]{2}{*}{$\left\langle\Delta \overline{H_{M L}}\right\rangle$} & 0.70 & -0.26 & -0.08 & 0.73 \\
\hline & 0.77 & -0.36 & -0.35 & 0.59 \\
\hline
\end{tabular}

687 TABLE 1. Correlation coefficients between $\left\langle\overline{w_{r m s}}\right\rangle,\left\langle\Delta \overline{H_{M L}}\right\rangle$, and each of $\left\langle\overline{R o_{b}}\right\rangle,\left\langle\frac{1}{2} \overline{\mathbf{u}_{m}^{2}}\right\rangle,\left\langle\overline{S_{m}}\right\rangle$, and $\left\langle\overline{\left|\nabla_{h} b\right|}\right\rangle$ from the $1 / 192^{\circ}$ simulation. Regions are indicated by font style - boldface font indicates values measured over the whole domain, standard font indicates values measured only in R1, and italic font indicates values measured only in R2. 


\section{LIST OF FIGURES}

Fig. 1. Domains of the nested models. The models are nested offline, running at $1 / 12^{\circ}, 1 / 24^{\circ}$, $1 / 48^{\circ}, 1 / 96^{\circ}$, and $1 / 192^{\circ}$ resolution. The domain size is reduced for the three highest resolution simulations. Each model features a $2^{\circ}$ sponge region (hatched lines) where the density and velocity fields are relaxed to the open boundary conditions. The meandering black lines are the time-mean $-0.7 \mathrm{~m}$ and $-0.25 \mathrm{~m}$ contours of sea surface height from the $1 / 12^{\circ}$ simulation, indicating the position of the Polar Front (southern line) and Subantarctic Front (northern line) according to the altimetry-based definitions of Sallée et al. (2008).

Fig. 2. a) Time-averaged mixed layer depth, $\overline{H_{M L}}$ from the $1 / 192^{\circ}$ model. b) Change in mixed layer depth between the $1 / 12^{\circ}$ and $1 / 192^{\circ}$ models, $\Delta \overline{H_{M L}}$. The mixed layer depth decreases in most places at higher resolution, reflected by positive values of $\Delta \overline{H_{M L}}$. The amplitude of the change varies with location. c) Base-10 logarithm of the time-averaged RMS vertical velocity, $\overline{w_{r m s}}$, from the $1 / 192^{\circ}$ model, which is also vertically averaged over the top $100 \mathrm{~m}$ of the ocean. The RMS velocity increases at higher resolution via an increasingly vigorous submesoscale field. The white line line indicates the 400-m isobath. The magenta boxes indicate regions which will be analysed in Figure 5.

Fig. 3. a) Snapshot of surface $\zeta$ from 30 June 2015 , in the $1 / 192^{\circ}$ model. b) Base-10 logarithm of the time-averaged Rossby number, $\overline{R o_{b}}$, as defined in Section b. Regions where the depth is shallower than $400 \mathrm{~m}$ have been grayed out.

Fig. 4. Base-10 logarithm of the surface a) mesoscale kinetic energy, $\frac{1}{2} \overline{\left|\mathbf{u}_{M}\right|^{2}}$, b) submesoscale kinetic energy, $\frac{1}{2} \overline{\left|\mathbf{u}_{S}\right|^{2}}$, and c) mesoscale strain rate, $\overline{S_{M}}$.

Fig. 5. Full-depth, spatially-averaged vertical profiles of the RMS vertical velocity from (a) R1 and (b) R2. Blue lines indicate the mesoscale component, ${\overline{\left(w_{r m s}\right)}}_{M}$, and red lines indicate the submesoscale component, ${\overline{\left(w_{r m s}\right)}}_{S}$. A histogram of the ocean depth in each region is presented by the gray bars.

Fig. 6. Scatter plots showing the trend of $\left\langle\overline{w_{r m s}}\right\rangle$ (left column) and $\left\langle\Delta \overline{H_{M L}}\right\rangle$ (right column) with $\left\langle\overline{R o_{b}}\right\rangle$ (top row), mesoscale KE (middle row), and mesoscale strain (bottom row). Blue, red, and gray dots indicate locations in R1, R2, and throughout the rest of the domain, respectively. Correlation coefficients appear in the bottom right corner of each panel. The black vertical lines are error bars, indicating one standard deviation above and below the mean.

Fig. 7. Maps of base-10 logarithm $\overline{\left|\nabla_{h} b\right|}$ from the a) $1 / 12^{\circ}$ and b) $1 / 192^{\circ}$ simulations, and scatter plots showing the trend of c) $\left\langle\overline{w_{r m s}}\right\rangle$ and d) $\left\langle\Delta \overline{H_{M L}}\right\rangle$ against $\left\langle\overline{\left|\nabla_{h} b\right|}\right\rangle$ from the $1 / 192^{\circ}$ simulation. Blue, red, and gray dots indicate locations in R1, R2, and throughout the rest of the domain, respectively. The black vertical lines are error bars, indicating one standard deviation above and below the mean.

Fig. 8. a) Map of $W$, the vertical velocity scaling (2) for waves generated at fronts undergoing large strain, diagnosed using the filtered mesoscale output variables from the $1 / 192^{\circ}$ simulations, compared with b) the model vertical velocity, $\overline{w_{r m s}}$. c) Scatter plot showing the trend of $\left\langle\overline{w_{r m s}}\right\rangle$ against $\langle W\rangle$. The black dashed line is the 1:1 line indicating perfect agreement between $W$ and $\overline{w_{r m s}}$. 
Fig. 9. Trend of $\left\langle\overline{w_{r m s}}\right\rangle$ as a function of horizontal resolution, where the spatial averaging is taken vertically over the top $400 \mathrm{~m}$ and horizontally over a) R1, b) R2, and c) the whole domain. Black vertical bars indicate the range of $\overline{w_{r m s}}$ values within each region. The numerical values are given in the tables on the right. Also shown in the tables are the values of $s$, the fractional increase in $\left\langle\overline{w_{r m s}}\right\rangle$ due to doubling the resolution. 


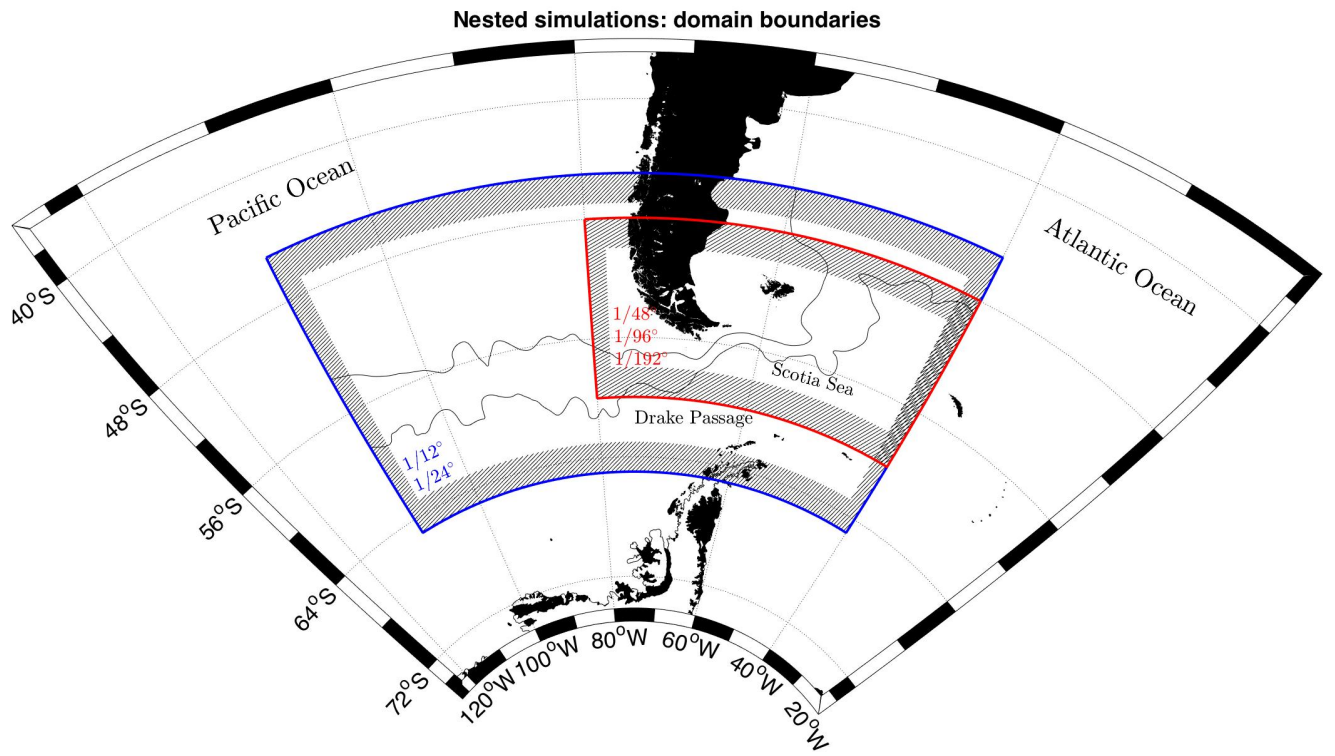

FIG. 1. Domains of the nested models. The models are nested offline, running at $1 / 12^{\circ}, 1 / 24^{\circ}, 1 / 48^{\circ}, 1 / 96^{\circ}$, and $1 / 192^{\circ}$ resolution. The domain size is reduced for the three highest resolution simulations. Each model features a $2^{\circ}$ sponge region (hatched lines) where the density and velocity fields are relaxed to the open boundary conditions. The meandering black lines are the time-mean $-0.7 \mathrm{~m}$ and $-0.25 \mathrm{~m}$ contours of sea surface height from the $1 / 12^{\circ}$ simulation, indicating the position of the Polar Front (southern line) and Subantarctic Front (northern line) according to the altimetry-based definitions of Sallée et al. (2008). 


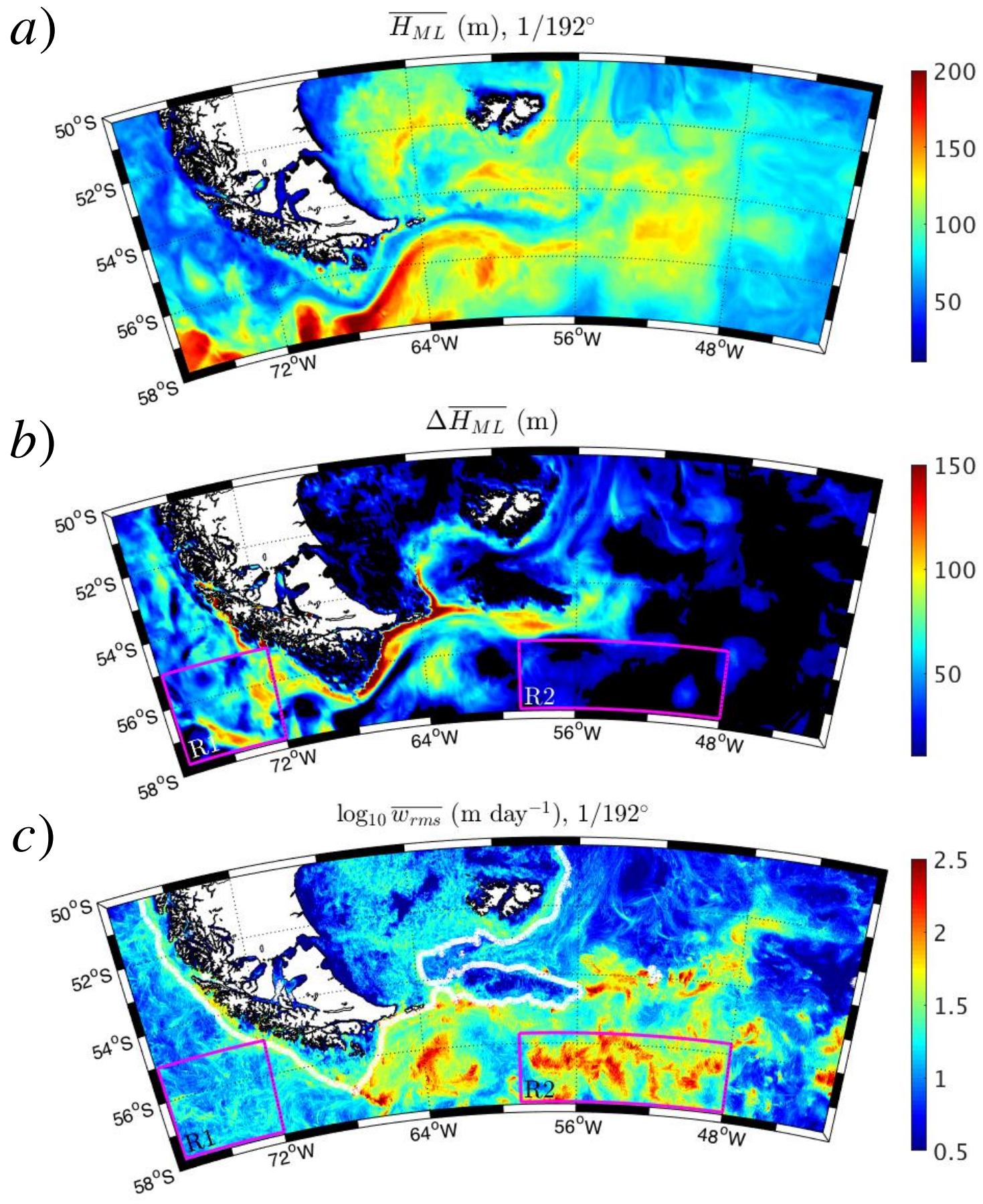

FIG. 2. a) Time-averaged mixed layer depth, $\overline{H_{M L}}$ from the $1 / 192^{\circ}$ model. b) Change in mixed layer depth between the $1 / 12^{\circ}$ and $1 / 192^{\circ}$ models, $\Delta \overline{H_{M L}}$. The mixed layer depth decreases in most places at higher resolution, reflected by positive values of $\Delta \overline{H_{M L}}$. The amplitude of the change varies with location. c) Base-10 logarithm of the time-averaged RMS vertical velocity, $\overline{w_{r m s}}$, from the $1 / 192^{\circ}$ model, which is also vertically averaged over the top $100 \mathrm{~m}$ of the ocean. The RMS velocity increases at higher resolution via an increasingly vigorous submesoscale field. The white line line indicates the $400-\mathrm{m}$ isobath. The magenta boxes indicate regions which will be analysed in Figure 5. 

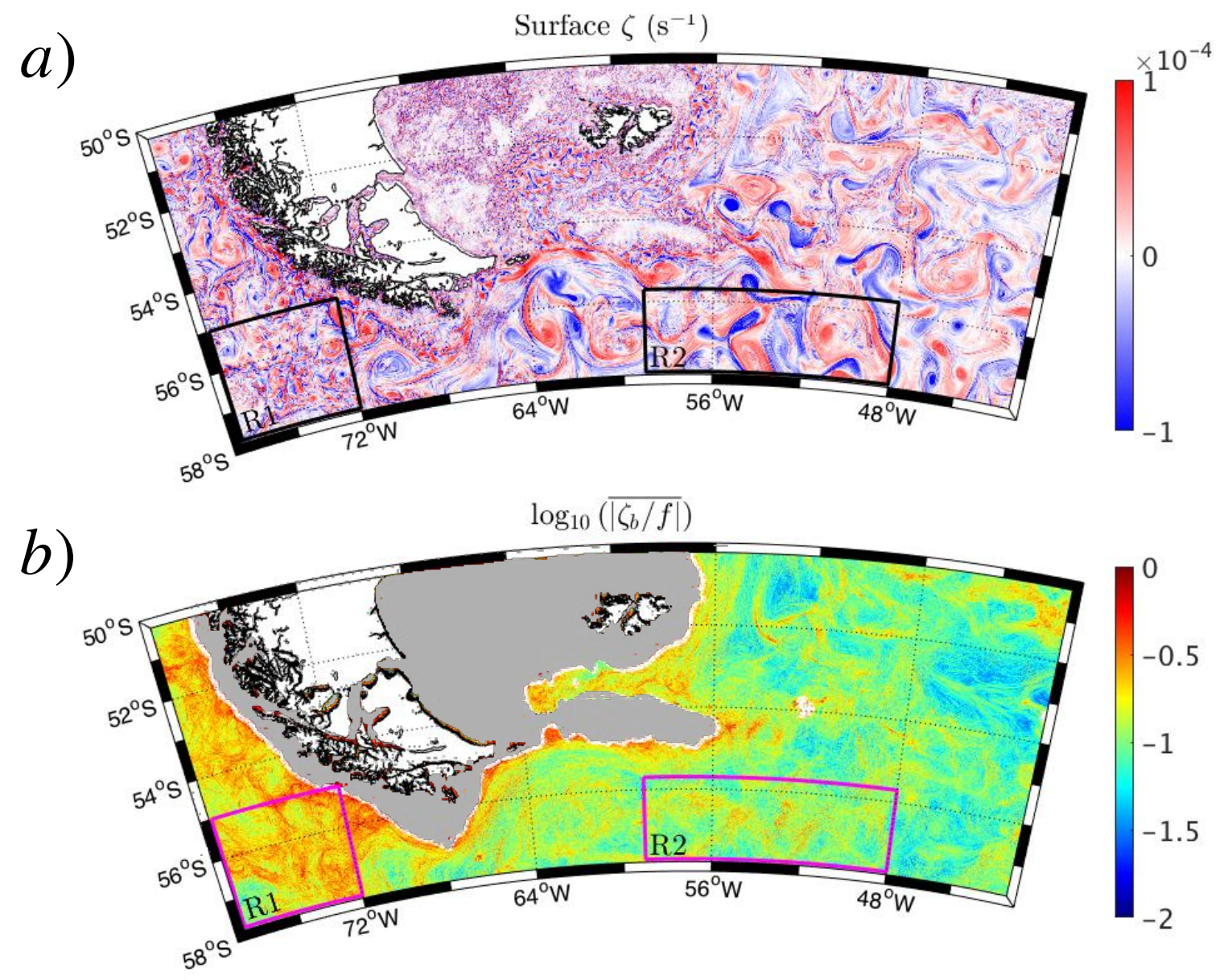

FIG. 3. a) Snapshot of surface $\zeta$ from 30 June 2015 , in the $1 / 192^{\circ}$ model. b) Base-10 logarithm of the timeaveraged Rossby number, $\overline{R o_{b}}$, as defined in Section b. Regions where the depth is shallower than $400 \mathrm{~m}$ have been grayed out. 

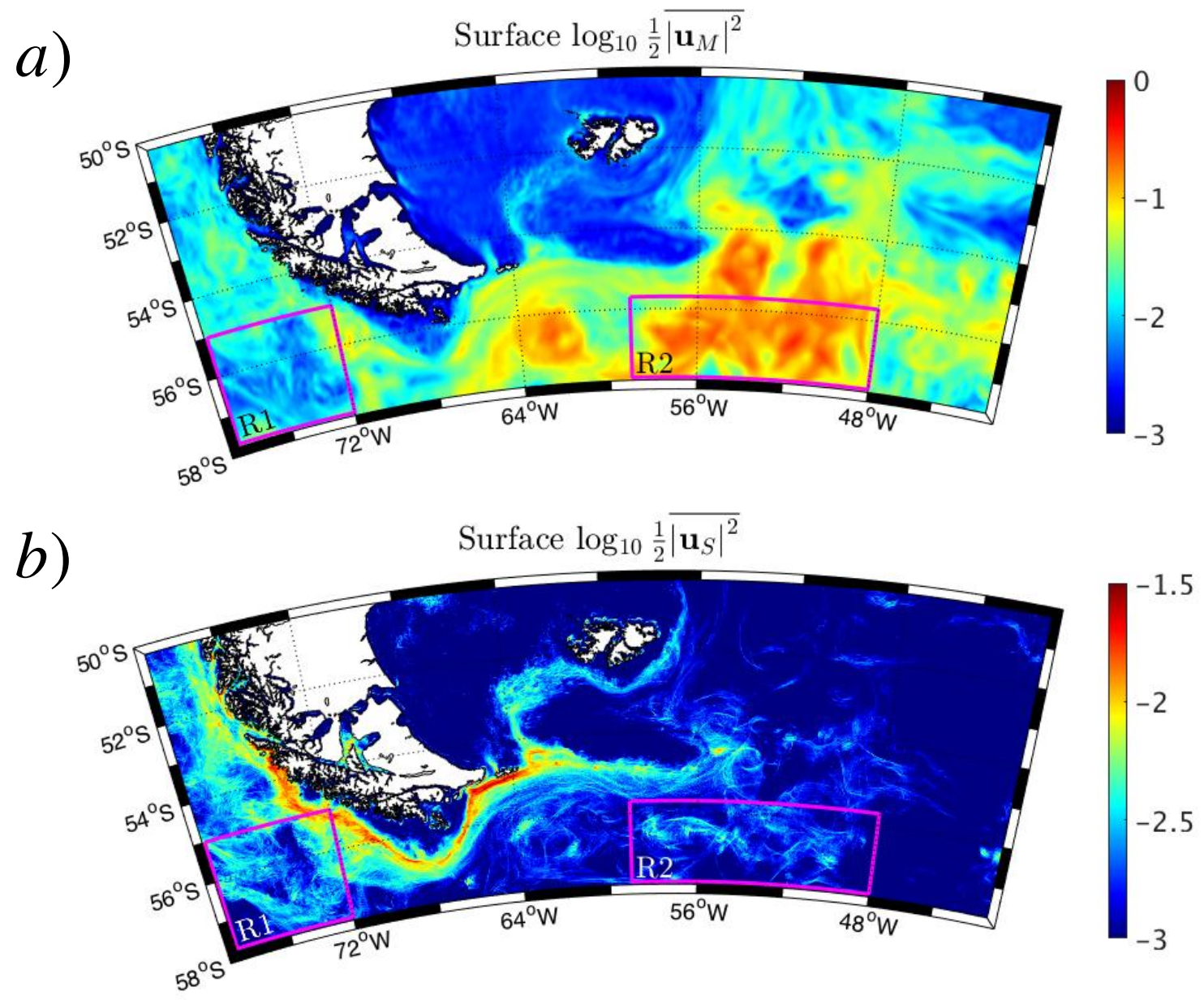

c)

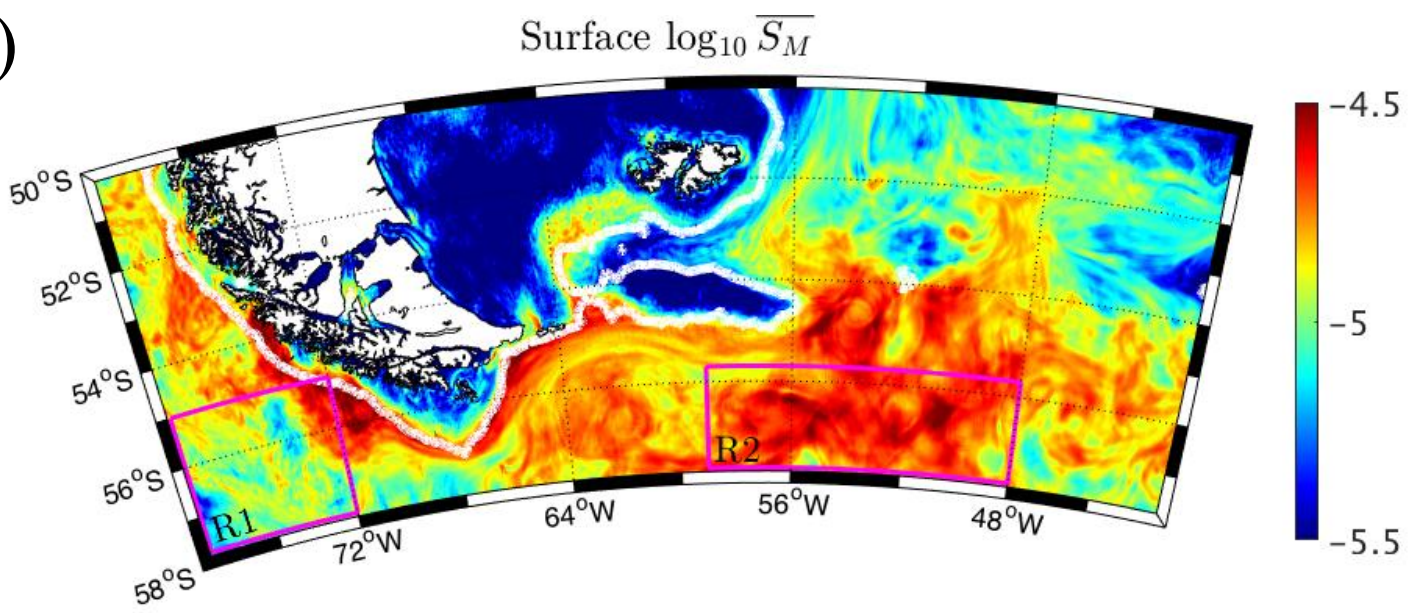

FIG. 4. Base-10 logarithm of the surface a) mesoscale kinetic energy, $\frac{1}{2} \overline{\left|\mathbf{u}_{M}\right|^{2}}$, b) submesoscale kinetic energy, ${ }_{754} \frac{1}{2} \overline{\left|\mathbf{u}_{S}\right|^{2}}$, and c) mesoscale strain rate, $\overline{S_{M}}$. 

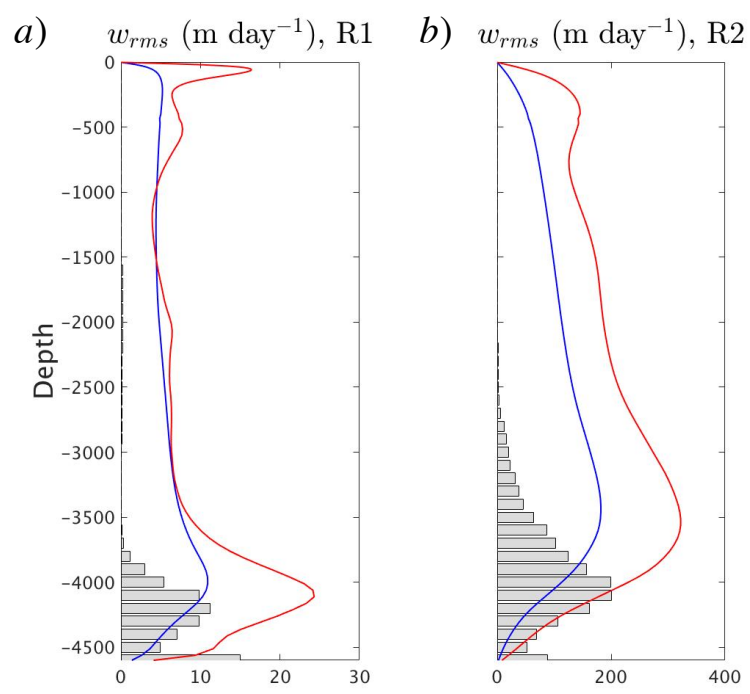

FIG. 5. Full-depth, spatially-averaged vertical profiles of the RMS vertical velocity from (a) R1 and (b) R2.

756 Blue lines indicate the mesoscale component, ${\overline{\left(w_{r m s}\right)}}_{M}$, and red lines indicate the submesoscale component, ${ }_{757} \overline{\left(w_{r m s}\right)_{S}}$. A histogram of the ocean depth in each region is presented by the gray bars. 

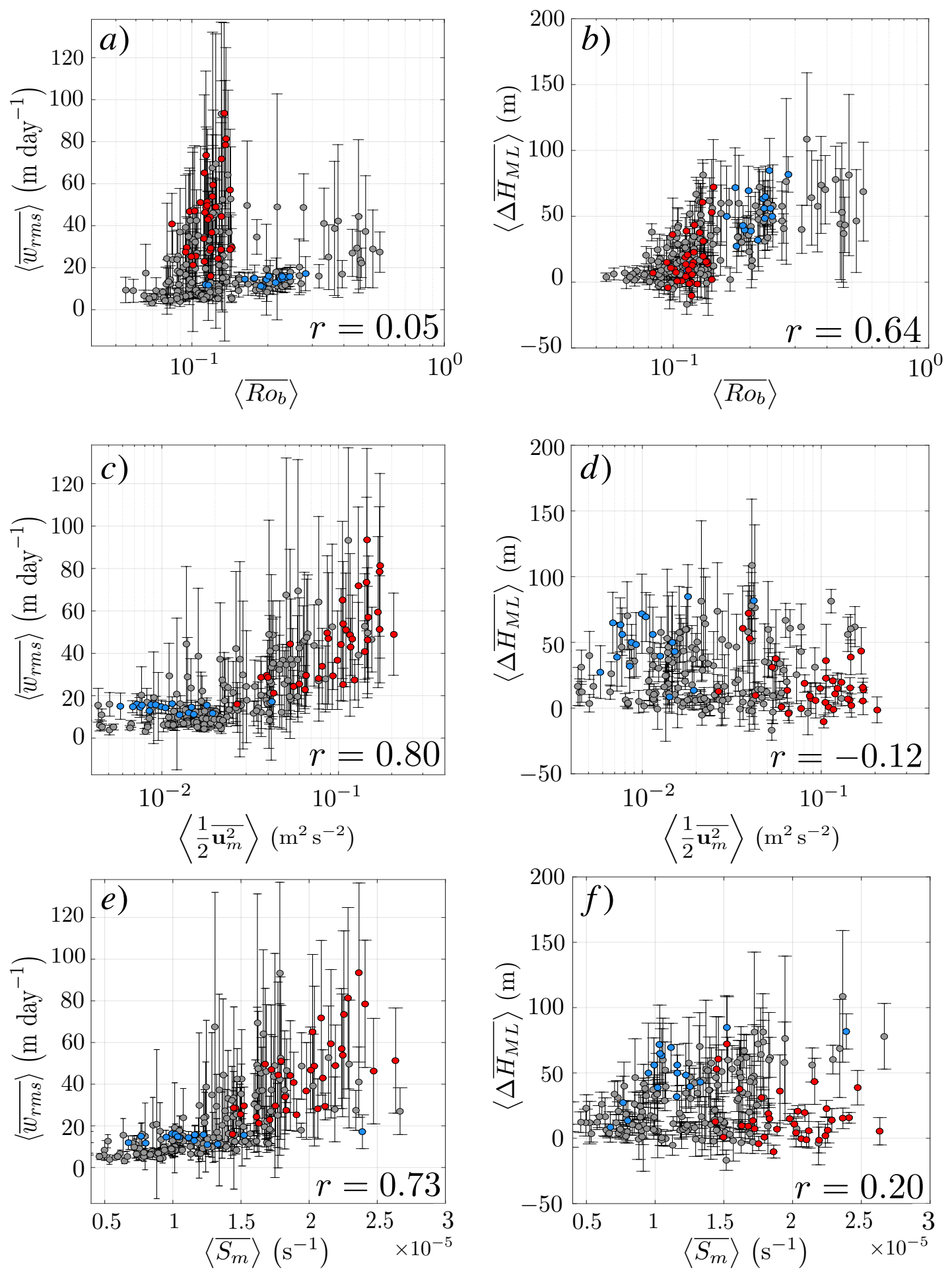

FIG. 6. Scatter plots showing the trend of $\left\langle\overline{w_{r m s}}\right\rangle$ (left column) and $\left\langle\Delta \overline{H_{M L}}\right\rangle$ (right column) with $\left\langle\overline{R o_{b}}\right\rangle$ (top , mesoscale KE (middle row), and mesoscale strain (bottom row). Blue, red, and gray dots indicate locations in R1, R2, and throughout the rest of the domain, respectively. Correlation coefficients appear in the bottom right corner of each panel. The black vertical lines are error bars, indicating one standard deviation above and below the mean. 

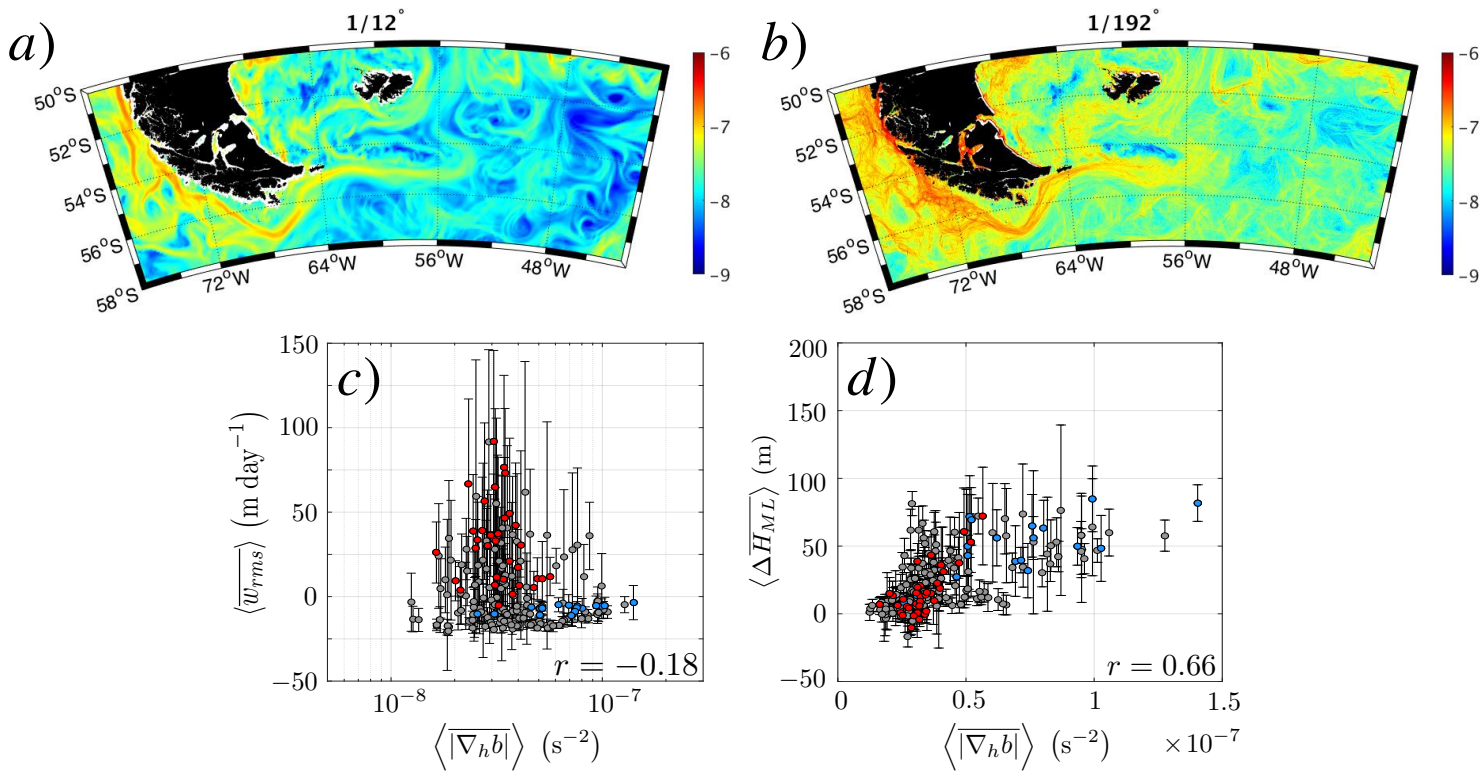

FIG. 7. Maps of base-10 logarithm $\overline{\left|\nabla_{h} b\right|}$ from the a) $1 / 12^{\circ}$ and b) $1 / 192^{\circ}$ simulations, and scatter plots showing the trend of c) $\left\langle\overline{w_{r m s}}\right\rangle$ and d) $\left\langle\Delta \overline{H_{M L}}\right\rangle$ against $\left\langle\overline{\left|\nabla_{h} b\right|}\right\rangle$ from the $1 / 192^{\circ}$ simulation. Blue, red, and gray dots indicate locations in R1, R2, and throughout the rest of the domain, respectively. The black vertical lines are error bars, indicating one standard deviation above and below the mean. 
a)

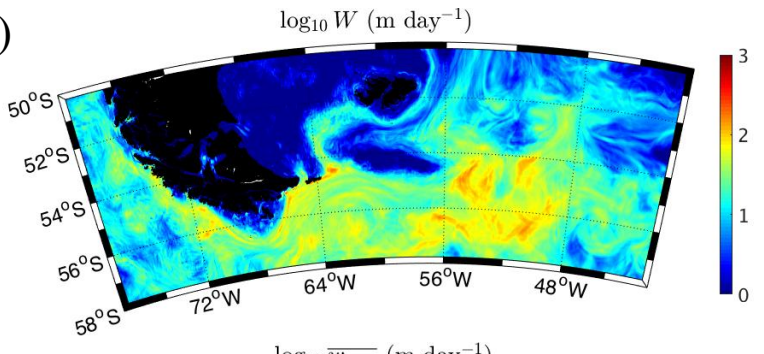

b)

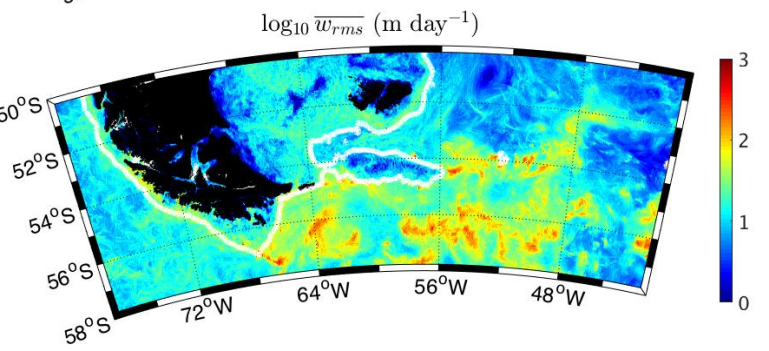

c)

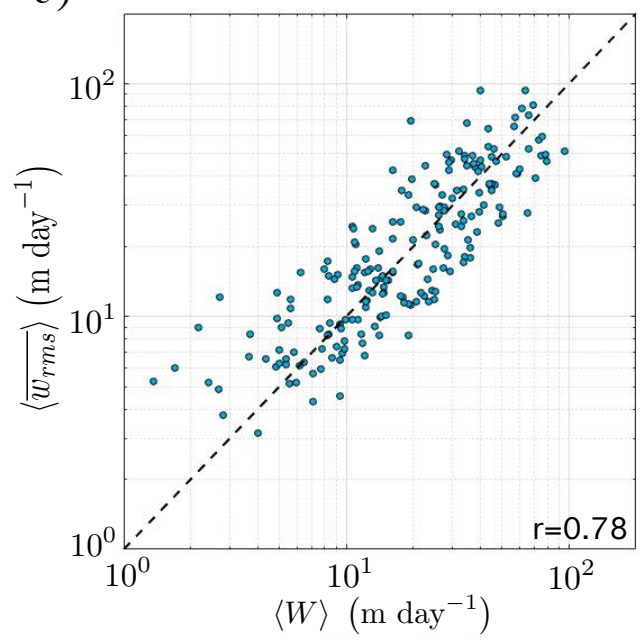

FIG. 8. a) Map of $W$, the vertical velocity scaling (2) for waves generated at fronts undergoing large strain, diagnosed using the filtered mesoscale output variables from the $1 / 192^{\circ}$ simulations, compared with $b$ ) the model vertical velocity, $\overline{w_{r m s}}$. c) Scatter plot showing the trend of $\left\langle\overline{w_{r m s}}\right\rangle$ against $\langle W\rangle$. The black dashed line is the 1:1 line indicating perfect agreement between $W$ and $\overline{w_{r m s}}$. 


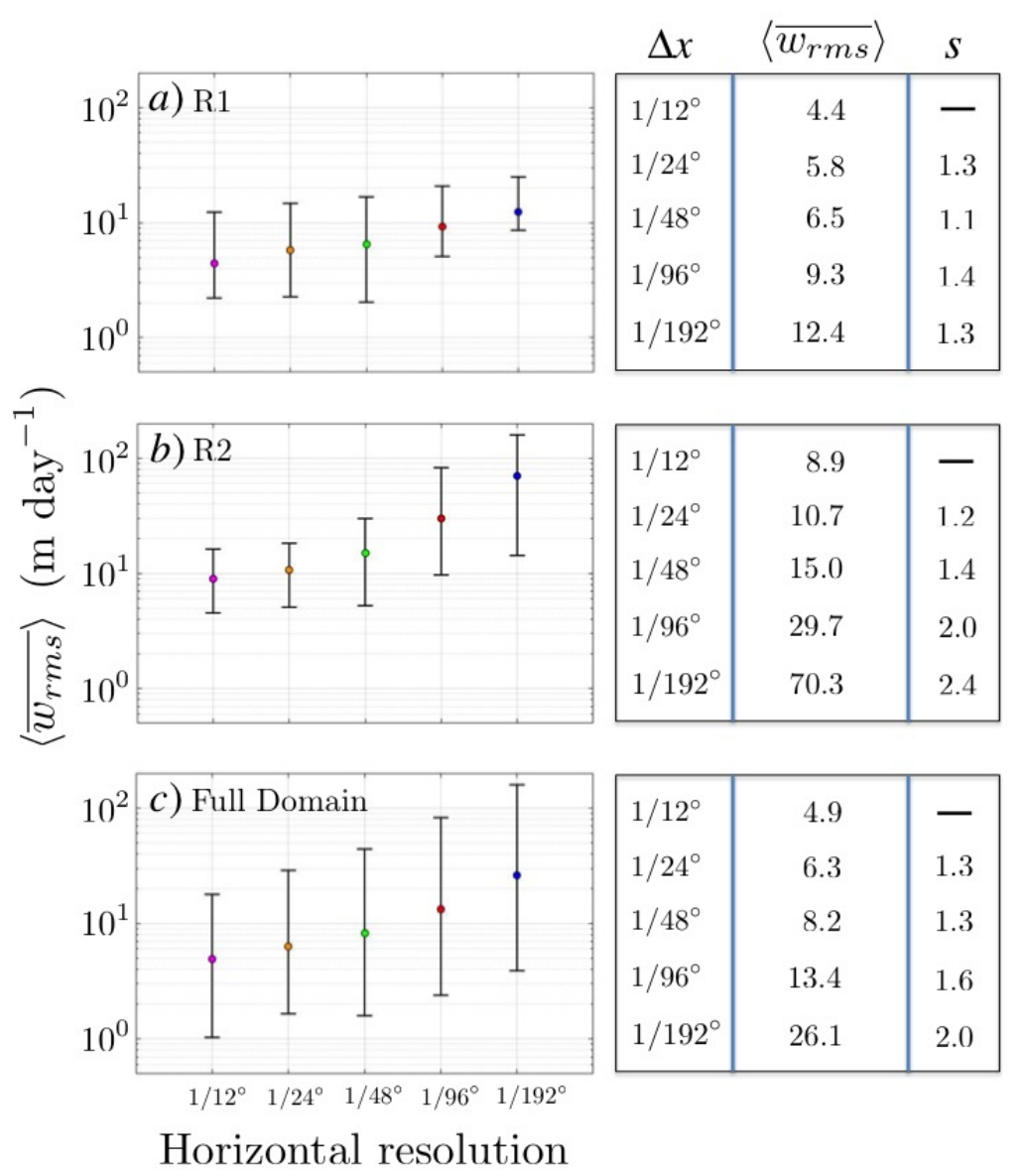

FIG. 9. Trend of $\left\langle\overline{w_{r m s}}\right\rangle$ as a function of horizontal resolution, where the spatial averaging is taken vertically over the top $400 \mathrm{~m}$ and horizontally over a) R1, b) R2, and c) the whole domain. Black vertical bars indicate the range of $\overline{w_{r m s}}$ values within each region. The numerical values are given in the tables on the right. Also shown in the tables are the values of $s$, the fractional increase in $\left\langle\overline{w_{r m s}}\right\rangle$ due to doubling the resolution. 